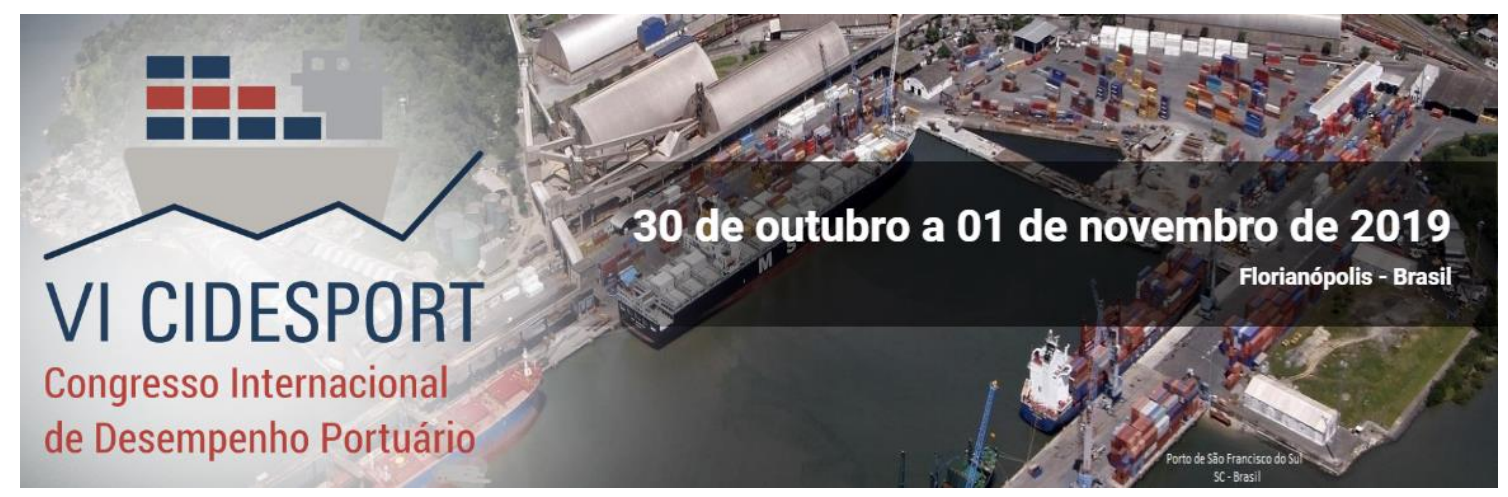

\title{
APOIO À GESTÃO DAS ATIVIDADES PORTUÁRIAS DE UMA HOLDING PÚBLICA: UMA ABORDAGEM CONSTRUTIVISTA DE AVALIAÇÃO DE DESEMPENHO PARA A SC PARTICIPAÇÕES E PARCERIAS S.A. - SC PAR
}

\author{
Daiana Pedersini \\ Universidade Federal de Santa Catarina \\ Lucas dos Santos Matos \\ Universidade Federal de Santa Catarina \\ Sandra Rolim Ensslin \\ Universidade Federal de Santa Catarina \\ Leonardo Ensslin \\ Universidade Federal de Santa Catarina
}

Resumo: Os portos são o canal preferencial para a ligação comercial dos países, o que faz deles o elo principal da cadeia logística de importações e exportações. O governo do estado de Santa Catarina, ciente da relevância dos portos em seu desenvolvimento particularmente econômico, incorporou, dentre seus objetivos estratégicos, o planejamento, o acompanhamento da gestão, a modernização, a ampliação e a construção de portos em sua área de influência, designando a holding SC Participações e Parcerias S.A. (SC Par) para o cumprimento de tais atribuições. Ao assumir tais obrigações, antes inexistentes, a nova diretoria da holding se questionou quanto à sua adequação estrutural e profissional para bem desempenhar as novas funções nos portos. Nesse contexto, a presente pesquisa tem como objetivo construir um modelo de apoio à gestão das atividades de planejamento portuário da SC Par, levando em consideração as particularidades dos seus gestores e do ambiente portuário. Para tanto, utilizou-se a metodologia Multicritério de Apoio à Decisão-Construtivista (MCDA-C). Valendo-se de entrevistas semiestruturadas, foram identificados nove objetivos, considerados necessários para avaliar a dimensão Planejamento das Atividades da holding SC Par, na qual foram construídas escalas ordinais e cardinais e foram identificadas as respectivas taxas de compensação. Com base no modelo construído, constatou-se que o desempenho da holding apresenta uma pontuação de 53 pontos, em uma escala de 0 a 100. Ou seja, embora a SC Par apresente um desempenho global em nível competitivo, em alguns aspectos apresenta performance de excelência, e em outros, comprometedora. O modelo subsidiou a geração de ações de melhoria, mostrando-se promissor em seus resultados para apoiar a SC Par a melhor atender suas atribuições relacionadas ao suporte dos portos subsidiários de SC. Cumpre salientar que a literatura analisada apontou uma preocupação centrada em aspectos operacionais dos portos subsidiários, demonstrando uma carência de trabalhos que se destinem a avaliar o processo de gestão. Nesse sentido, a construção do modelo Construtivista, para

\footnotetext{
* A revisão gramatical, ortográfica, ABNT ou APA foi realizada pelos autores.
} 
VI CIDESPORT/2019

Congresso Internacional

de Desempenho Portuário

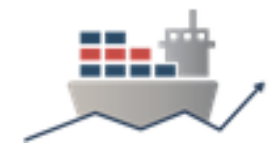

apoiar a gestão das atividades de planejamento portuárias da SC Par, observando suas particularidades, contribuiu para a geração de conhecimentos literário e empírico.

Palavras-chave: Setor Portuário. Holding. Avaliação de Desempenho. Gestão. Planejamento. Modelo Multicritério. Abordagem Construtivista.

\section{INTRODUÇÃO}

As relações econômicas, sociais, culturais e políticas, propiciadas pelas redes de conexões entre os países, a partir de 1990, permitiram a realização de transações comerciais sem restrições geográficas e/ou ideológicas. Esse aumento das interações notadamente mercantis passou a demandar estruturas logísticas multiconectadas, ágeis, confiáveis, seguras e econômicas. Os portos, como elo dessa cadeia, passam então a ter função de destaque no estabelecimento da competitividade das nações (Ngoc \& Moon, 2011; Pessanha et al., 2013).

Segundo dados da UNCTAD (2019), cerca de $80 \%$ do volume de cargas internacionais são transportados por meios marítimos. Nesse sentido, os portos cumprem, além da conexão entre diferentes países, um papel fundamental no desenvolvimento econômico regional, devido ao grande volume de cargas movimentadas (Munisamy \& Singh, 2011). Há concordância de que os portos contemplam uma ligação essencial no comércio mundial que coopera para a competitividade (Tongzon, 1989; Chin \& Tongzon, 1998), a qual vem se intensificando, exigindo a avaliação da eficiência operacional, para que os portos possam avaliar seu desempenho atual e entender seus pontos fortes e fracos no ambiente em que estão inseridos (Munisamy \& Singh, 2011).

No Brasil, a discussão referente à relevância dos portos, no contexto econômico, recebeu mais atenção a partir da década de 1990, com a abertura do mercado portuário às organizações de iniciativa privada, com a promulgação da Lei de Modernização dos Portos. Dessa forma, as organizações têm procurado evoluir seus processos de gestão de modo a acompanhar e criar diferenciais competitivos para se destacarem no mercado. No estado de Santa Catarina, a iniciativa do governo, buscando a geração de investimentos no território estadual, criou a SC Participações e Parcerias S.A. (SC Par), que, dentre suas atribuições, possui a responsabilidade da gestão dos portos de interesse público do Estado, por meio de uma estrutura de controle acionário (holding).

Contudo, devido às recentes transformações demandadas na atual gestão dos portos de Santa Catarina, a SC Par ainda busca construir conhecimento nas organizações subsidiárias, suas atividades complexas, e definir as exigências mínimas necessárias para a adequada gestão e acompanhamento das operações portuárias que, até o início de 2019, não foram feitas de forma efetiva. Com isso, há dúvidas sobre qual é o desempenho esperado pelo governo estadual com relação aos portos de Santa Catarina. Assim, questiona-se se a SC Par está preparada para gerir os portos catarinenses.

Nesse contexto, com o intuito de possibilitar um instrumento de gestão que apoie a tomada de decisão da holding e permita o aperfeiçoamento do seu desempenho, emerge esta questão de pesquisa: Quais indicadores devem ser considerados em um instrumento que apoie a gestão das atividades de uma holding portuária? A fim de responder a essa questão, o objetivo deste estudo é construir um 
VI CIDESPORT/2019

Congresso Internacional

de Desempenho Portuário

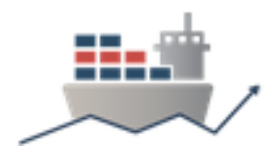

modelo de apoio à gestão das atividades portuárias da SC Participações e Parcerias S.A., considerando as particularidades dos seus gestores e do ambiente portuário.

Para atender ao objetivo proposto, selecionou-se a metodologia Multicritério de Apoio à Decisão-Construtivista (MCDA-C) (Ensslin, Giffhorn, Ensslin, Petri \& Viana, 2010; Matos, Valmorbida, \& Ensslin, 2018), que utiliza as percepções e os valores do(s) decisor(es) para a construção de um modelo de gestão intimamente relacionado às suas necessidades e expectativas.

Este trabalho se justifica por sua relevância, originalidade e viabilidade, conforme defende Castro (1977). E relevante, pois contribui para o aprofundamento literário relacionado ao papel de gestão por holdings na área portuária, tendo em vista que os estudos encontrados (Albert, 2015; Blackwell, Brickley, \& Weisback, 1994; Brighi \& Venturelli, 2014; Pat Obi, \& Emenogu, 2003; Wang, Lu, \& Liu, 2014) preocupam-se com as operações portuárias, e não com a gestão da holding. Além disso, na literatura analisada, não foram encontrados outros trabalhos que utilizassem a metodologia MCDA-C como instrumento de intervenção, tornando-se isso uma oportunidade de pesquisa. Sua originalidade se encontra no fato da existência de um problema interno da organização, alvo deste estudo, em decorrência das mudanças acionárias e, também, devido ao ineditismo dessa situação no País, onde não se encontram outros portos públicos geridos por holding. Dessa forma, a SC Par necessita de um instrumento de apoio à gestão de suas atividades de planejamento portuário. Ainda, considera-se a pesquisa como viável, tendo em vista a interação que ocorre entre o decisor de assuntos portuários e os autores desta pesquisa para 0 desenvolvimento de um instrumento que permita a expansão de conhecimento relacionado ao contexto de atuação da holding e que apoiará a atividade de gestão da SC Participações e Parcerias S.A.

Cabe mencionar que este estudo se limita a apresentar o modelo de Avaliação do Desempenho $(\mathrm{AD})$ da holding referente à dimensão (Ponto de Vista Fundamental) de Planejamento.

\section{PROCEDIMENTOS METODOLÓGICOS}

\subsection{Procedimento para seleção do material para revisão da literatura}

Para a construção do referencial teórico, optou-se por um processo com abordagem Construtivista para fazer a seleção dos artigos que serviram de base para a construção de conhecimento a respeito do tema (Staedele, Ensslin, \& Forcellini, 2019). Dessa forma, utilizou-se o Knowledge Development Process-Constructivist (ProKnow-C) (Dutra, Ripoll-Feliu, Fillol, Ensslin, \& Ensslin, 2015), de modo que, com base na percepção dos autores, fosse possível selecionar um Portfólio Bibliográfico (PB) referente à Avaliação de Desempenho em holdings e estudos realizados em holdigns portuárias. A Figura 1 apresenta um resumo do processo de seleção. 

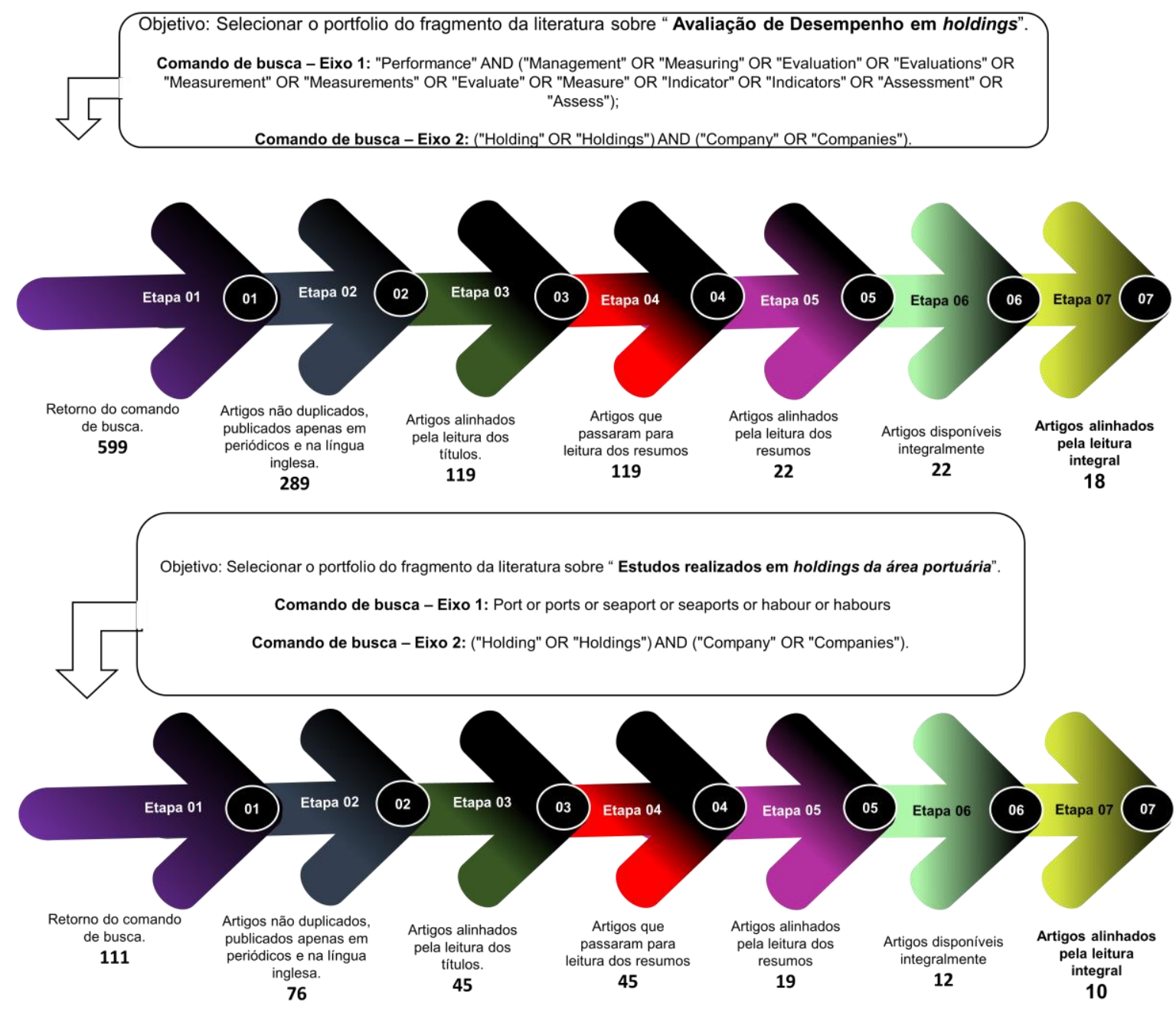

Figura 1 - Resumo do processo de seleção dos artigos

As buscas foram feitas nas bases de dados Web of Science e Scopus, por se tratarem de bases de uso internacional, que buscam avaliar a relevância das publicações (Matos, Valmorbida, Martins, \& Ensslin, 2019). Os artigos selecionados representam um fragmento da literatura relacionada ao tema e, portanto, servirão de base para a construção do referencial teórico e posterior discussão dos resultados. Dessa forma, os artigos selecionadaos encontram-se listados nas referências, identificados com colchetes [ ] e o termo "AD" para o eixo de Avaliação de Desempenho em holdings, e "HP" para estudos realizados em holdings, na área portuária.

\subsection{Instrumento para construção do modelo Multicritério Construtivista}

Para execução do objetivo proposto, esta pesquisa segue a metodologia Multicritério de Apoio à Decisão-Construtivista (MCDA-C) como instrumento de intervenção, considerando que essa metodologia possui uma abordagem Construtivista, a qual permite a participação do decisor durante todo o processo, conhecendo os impactos de suas decisões, que são sustentadas por seus valores e suas preferências (Ensslin, Dutra, \& Ensslin, 2000).

Dessa forma, a metodologia MCDA-C tem como intuito principal o desenvolvimento do conhecimento no gestor sobre o contexto no qual está inserido, quando ele não tem entendimento claro de seus interesses, e seus critérios de 
avaliação ainda não estão bem definidos (Ensslin et al., 2010; Matos, Valmorbida, \& Ensslin, 2018). Esse processo se desenvolve de forma sistêmica e sistemática por meio de três fases: (i) Estruturação, (ii) Avaliação e (iii) Recomendações, conforme demonstrado na Figura 2.

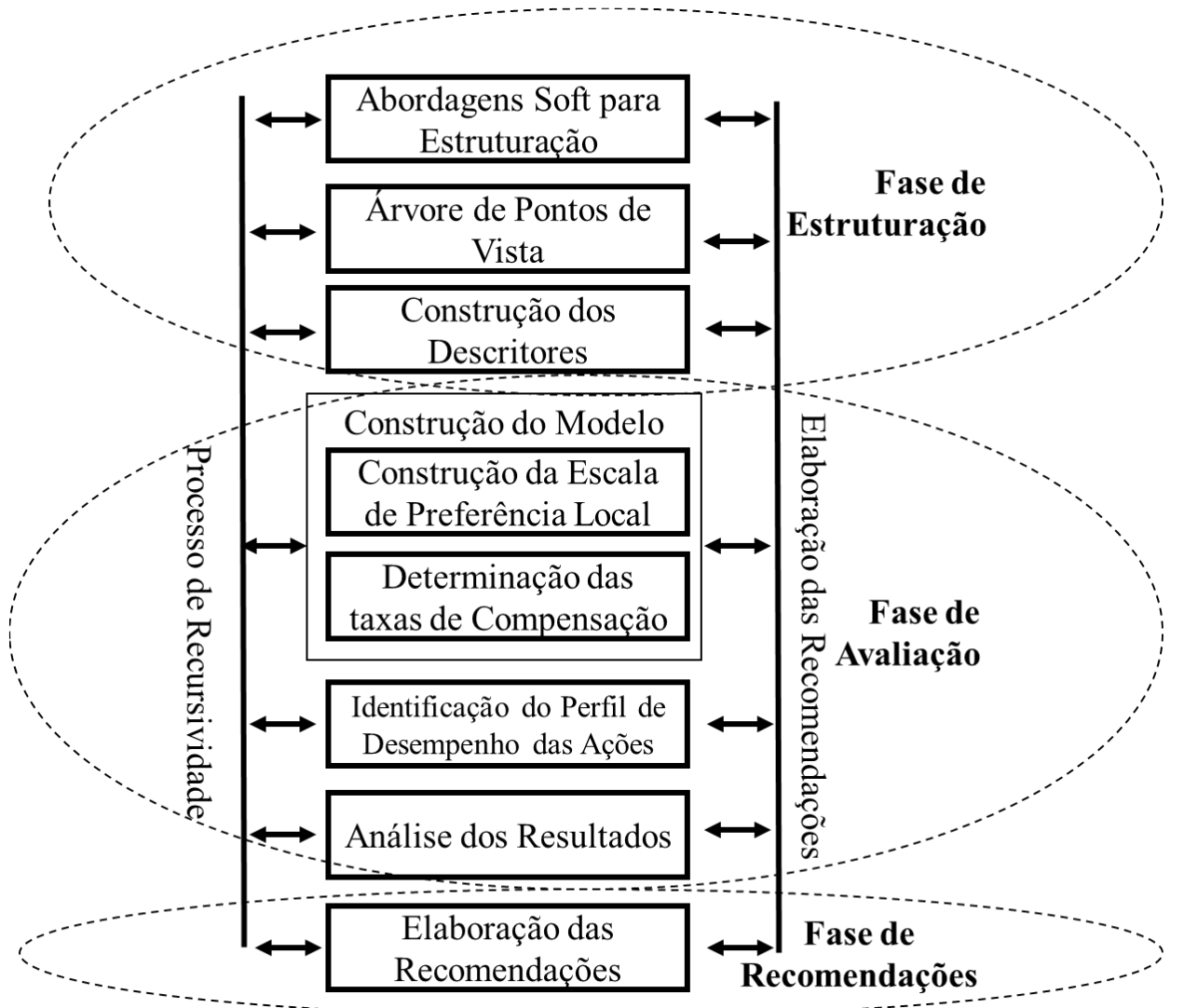

Figura 2 - Fases da Metodologia Multicritério de Apoio à Decisão-Construtivista Fonte: traduzido de Ensslin, Dutra e Ensslin (2000, p. 81).

Esta pesquisa desenvolverá as três fases da metodologia a fim de construir um instrumento que oriente a gestão das atividades de planejamento portuário da SC Participações e Parcerias S.A.

A primeira fase, Estruturação, consiste em identificar os aspectos que o decisor julga como relevantes, necessários e suficientes para se considerarem no processo de Avaliação de Desempenho de acordo com seus valores e preferências (Ensslin et al., 2010). Assim, busca-se a construção de conhecimento no decisor a respeito do problema que se quer resolver por meio da identificação dos aspectos julgados como relevantes e evidenciados em uma Estrutura Hierárquica de Valor (EHV) (Ensslin, Montibeller, \& Noronha, 2001; Keeney, 1992). A EHV possibilita ao gestor a visualização dos aspectos que interferem no processo decisório, decompondo-os até seus níveis operacionais, nos quais é possível construir os descritores (escalas ordinais) (Bana e Costa \& Silva (1994) que representam como cada aspecto será avaliado no contexto em questão (Longaray et al., 2018; Rodrigues, Fernandes, Rodrigues, Bortoluzzi, Costa, \& de Lima, 2018). Nessa fase, também são estabelecidos os níveis de referência (denominados Neutro e Bom) que permitem a separação dos níveis da escala ordinal em excelente, competitivo e comprometedor (Ensslin, Dutra, \& Ensslin, 2000). Com isso, pode-se traçar o perfil de desempenho, ou seja, identificar o statu quo da ação ou do contexto que se pretende avaliar (Bortoluzzi, Ensslin, \& Ensslin, 2010). Adicionalmente, os níveis de referência irão 
contribuir para a transformação das escals ordinais em cardinais (construção da funções de valor) e das taxas de compensação.

A fase de Avaliação tem como intuito principal transformar o modelo qualitativo, inicialmente construído, em um modelo matemático. Nessa etapa, utiliza-se o software Macbeth (Mensuring Attractiveness by a Categorical Based Technique)(Bana e Costa \& Vansnick, 1997) para a construção das funções de valor, para cada um dos descritores, e para a identificação das taxas de compensação. Cumpre observar que 'o que será avaliado' (aspecto), acrescido das informações de 'como será avaliado' (escala ordinal) e de 'quanto vale' (qual a respectiva mensuração de cada nível da escala), foi um 'critério' ou popularmente conhecido como indicador. As funções de valor permitem a avaliação local do desempenho (em cada descritor), $\mathrm{e}$ as taxas de compensação permitem a avaliação global do desempenho. Finalmente, a fim de se obter uma pontuação global do desempenho (statu quo), fazse uso da equação de agregação aditiva, proposta por Ensslin, Dutra e Ensslin (2000, p. 87):

$$
\mathrm{V}(\mathrm{a})=\sum_{\mathrm{j}=1}^{\mathrm{m}} \mathrm{w}_{\mathrm{j}} \cdot\left(\mathrm{V}_{\mathrm{FPV}_{\mathrm{J}}} \cdot(\mathrm{a})\right)
$$

onde:

$\Rightarrow \mathrm{V}(\mathrm{a})$ é a pontuação da avaliação global de $\mathrm{a} \in \mathrm{A}$;

$\Rightarrow$ A é o conjunto de possíveis ações/alternativas ou contexto;

$\Rightarrow \mathrm{w}_{\mathrm{j}}$ é a taxa de compensação do critério j;

$\Rightarrow\left(V_{F P V j}(a)\right)$ é o impacto da ação/alternativa/contexto $A$, em relação ao $F P V_{j}$.

A análise de sensibilidade completa a fase de Avaliação com o objetivo de verificar a robustez das taxas de compensação identificadas.

Já na fase de Recomendações, com base no statu quo identificado, são propostas ações que possibilitem influenciar de forma positiva o atual desempenho. Assim, as sugestões de ações constituem-se como uma atividade de gestão ao constituírem-se como alternativas de possíveis rumos a serem tomados, acompanhados da evidenciação de seus respectivos impactos e pontuação global do modelo, ofertadas ao gestor (Ensslin, Dezem, Dutra, Ensslin, \& Somensi, 2017).

\section{REFERENCIAL TEÓRICO}

Para fundamentar esse trabalho, buscou-se por estudos relacionados ao tema central deste artigo, referentes à Avaliação de Desempenho em holdings no setor portuário. No entanto, não houve retorno de estudos relacionados diretamente ao tema nas bases de dados pesquisadas. Desse modo, devido à falta de retorno de estudos referentes ao tema, buscou-se desenvolver o referencial teórico sob duas perspectivas: (i) Avaliação de Desempenho em holdings; e (ii) Estudos em holdings portuárias.

\subsection{Avaliação de Desempenho em holdings}

A Avaliação de Desempenho (AD) exerce um papel fundamental nas organizações, considerando que é capaz de promover informações aos seus usuários relacionadas ao desempenho organizacional, por meio de um feedback sobre a eficácia de suas ações (Sun, 2011). As mudanças decorrentes das exigências do 
mercado de trabalho $e$ as estruturas socioeconômicas têm acelerado o desenvolvimento e a profissionalização da gestão organizacional, gerando a necessidade de adaptação às novas premissas, objetivando o desempenho pleno (Pipas, 2015). Dessa forma, a AD pode ser visualizada como um guia, ou orientação, de como as ações organizacionais devem ser desenvolvidas, clarificando seu entendimento e facilitando o processo da tomada de decisões (Tehrani, Mehragan, \& Golkani, 2012).

Com o crescimento da diversificação e volume de investimentos, bem como das diferentes fontes de informações, a $A D$ começou a ser vista como uma necessidade dentro das organizações, principalmente com relação às abordagens de parceria corporativa, na qual as sociedades anônimas passaram a ter mais complexidades no desenvolvimento de negócios (Tehrani, Mehragan, \& Golkani, 2012). Segundo Higgins e Toms (2013), a utilização de estruturas organizacionais adequadas, correspondentes à estratégia do ambiente, possibilita obter uma vantagem competitiva por períodos mais prolongados e geração de melhores retornos.

Sales e Carenys (2012) apontam que o processo de gestão precisa ser adaptado de forma a suprir a estratégia do negócio de acordo com as especificações. Nesse contexto, faz-se necessário desenvolver a estratégia identificando e adotando medidas de desempenho que possibilitem atingir as metas estabelecidas. $O$ aumento da concorrência, nos diversos setores da economia, faz com que as organizações estejam mais atentas ao desempenho eficiente, reforçando que a formatação de negócios utilizada interfere nos resultados organizacionais, e a estrutura de propriedade (holding) com subsidiárias possibilita a redução de custos de informação e melhoria da competitividade (Zhu, Chen, \& White, 2014).

Andrews, Carpentier e Gowen (2001) relatam, em seu estudo, evidências de que a implementação de um Sistema de Avaliação de Desempenho (SAD) permitiu que a holding aprimorasse sua forma de autoavaliação e autoplanejamento de desempenho com relação às suas subsidiárias. Adicionalmente, Hu, Lai e Huang (2009) identificaram que, com o crescimento do setor financeiro, cresce também a necessidade de a holding ser gerida de forma eficiente. Consequentemente, esse fator gera um ambiente estável e atrai o interesse de investidores globais (Liu, 2011).

Diversos estudos vêm sendo desenvolvidos a fim de verificar a eficiência de holdings, principalmente relacionados ao setor bancário (Albert, 2015; Blackwell, Brickley, \& Weisback, 1994; Brighi \& Venturelli, 2014; Pat Obi, \& Emenogu, 2003; Wang, Lu, \& Liu, 2014). Há ainda estudos que avaliam o impacto da estrutura corporativa da holding na gestão, identificando que essa estrutura fornece flexibilidade para apoiar a estratégia (Higgins \& Toms, 2013), que a estrutura busca inserir técnicas modernas em sua gestão (Morrison, 2007) e que a adesão pela nova estrutura (holding) traz melhorias na eficiência organizacional (Hess, 2010; Yeh, Wang, \& Chai, 2010).

Dessa forma, compreende-se que a inserção da Avaliação de Desempenho no contexto organizacional possibilita aumentar os níveis de competitividade e transparência, pois trata-se de um processo que proporciona a autoavaliação (Tehrani, Mehragan, \& Golkani, 2012). Além disso, as preferências dos indivíduos que estão à frente do negócio têm influência significativa na concepção de indicadores (Sales \& Carenys, 2012), e a utilização das percepções dos gestores gera melhores resultados, pois a estratégia só tem significado se for aceita e discutida dentro do ambiente organizacional (Lowe \& Jones, 2004), construindo, assim, o processo de aprendizagem contínua. 
VI CIDESPORT/2019

Congresso Internacional

de Desempenho Portuário

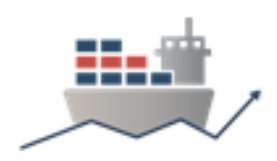

\subsection{Estudos em holdings portuárias}

O papel de gestão que uma autoridade portuária, por meio de uma holding, exerce dentro de um grupo empresarial provê uma força para intensificar a implementação da estratégia nas empresas subsidiárias (Zurek, 1997), de modo que as subsidiárias tenham um papel mais orientado para as atividades operacionais, cumprindo os objetivos da organização completamente. Ainda, a autoridade portuária deve fornecer as orientações necessárias para gerenciar o desenvolvimento dos portos, bem como promover a busca por mais investimentos na estrutura (Chen, Pateman, \& Sakalayen, 2016; Pessanha, Gomes Filho, Júnior, Neto, \& Oliveira, 2013) e melhorar suas operações (Agnarsson, Matthiasson, \& Giry, 2016; Randrianarisoa \& Zhang, 2019). Nesse contexto, as empresas de transporte marítimo têm se preocupado em estabelecer ferramentas de apoio à decisão que possibilitem otimizar recursos e melhorar seu planejamento em termos operacionais (Wang \& Meng, 2012).

Com o intuito de obter economias de escalas crescentes, o transporte marítimo tem apresentado grandes mudanças em decorrência das pressões impostas pela concorrência desse mercado (Mirodo \& Parola, 2002). Estudos relacionados à gestão portuária, por meio de holdings (Chen, Zhang, \& Liu, 2016; Li, Liu, Leung, \& Lai, 2004; Ngoc \& Moon, 2011; Pessanha et al., 2013), preocupam-se, em sua maioria, com a redução de custos nas operações portuárias, eficiência dos investimentos efetuados e a relação do pagamento de executivos de acordo com os benefícios gerados. Nesse sentido, os objetivos dos estudos têm se mostrado mais relacionados a aspectos operacionais dos portos, em detrimento de discussões que abordem o papel estratégico da holding e sua importância para a gestão dos portos.

Esses fatores levantam uma questão latente em relação aos estudos em holdings do setor portuário. Pouco ou nada se discute na literatura em relação ao papel de direcionador estratégico da holding nesse setor. A literatura carece de estudos que considerem a holding como centralizadora das ações do grupo, agindo como agente de prospecção de investimentos e definidora de metas e objetivos para o grupo, observando a busca pela melhoria contínua no grupo empresarial.

\section{CONSTRUÇÃO DO MODELO DE AVALIAÇÃO DE DESEMPENHO}

\subsection{Fase de Estruturação}

Segundo Ensslin et al. (2010), na fase de Estruturação, o contexto estudado é estruturado por meio dos aspectos considerados como relevantes pelo decisor. Nessa fase, identificam-se os subsistemas de atores, um rótulo que represente a preocupação central do decisor e são organizados e mensurados ordinalmente os objetivos identificados que os decisores julgam como necessários e suficientes ao contexto.

\subsubsection{Contextualização, subsistema de atores e rótulo}

A pesquisa foi desenvolvida em uma holding pública no estado de Santa Catarina, a qual detém o controle acionário de duas subsidiárias. Sua criação ocorreu em 2005 pelo governo do Estado com o intuito de gerar investimentos no território estadual. Dentre suas atribuições, está a ampliação, modernização e construção de portos. O direito de exploração de portos faz com que a empresa busque meios de gerir os portos de interesse público (Imbituba e São Francisco). Entretanto, ainda não 
VI CIDESPORT/2019

Congresso Internacional

de Desempenho Portuário

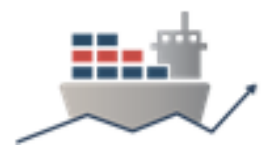

há um padrão utilizado para essa gestão, fazendo com que surja a preocupação de estabelecer padrões mínimos de avaliação, buscando identificar quais são as exigências a serem demandadas aos portos públicos delegados de Santa Catarina. Diante do exposto, foram identificados quais os atores estariam envolvidos no processo, causando interferência ou possuindo interesse nas decisões a serem tomadas. A Figura 3 demonstra o subsistema de atores envolvidos.

\begin{tabular}{|c|c|c|}
\hline की & Decisor & Executivo de assuntos portuários \\
\hline 竞 & Intervenientes & $\begin{array}{l}\text { Antaq } \\
\text { SNP } \\
\text { Diretores dos portos } \\
\text { Diretores da holding }\end{array}$ \\
\hline & Facilitador & Autores \\
\hline & Agidos & \begin{tabular}{|l} 
Portos de Imbituba e São \\
Francisco \\
Receita Federal \\
Órgãos Reguladores
\end{tabular} \\
\hline
\end{tabular}

Figura 3 - Subsistemas de atores

Após a identificação apresentada, em uma interação de facilitadores e decisor e por meio das suas percepções, definiu-se como rótulo para abordagem do problema "Construir um modelo de avaliação da holding frente aos portos delegados de SC". Considerando que, para a construção do modelo, é preciso desenvolver o conhecimento nos decisores para a identificação dos aspectos considerados necessários, elaborou-se um checklist inicial com 15 perguntas abertas que orientaram as entrevistas feitas in loco com o decisor. A Figura 4 apresenta algumas das questões utilizadas.

1 - Quais aspectos você considera que a SC Par deve 'possuir', 'fazer' e 'desenvolver' para ser capaz de gerir suas subsidiárias?

2 - Quais ações são atualmente realizadas pela holding para gerir os portos catarinenses?

3 - Quais ações não são realizadas pela SC Par, independente da razão, que você considera ser importante na atividade de gestão da SC Par frente aos portos?

Figura 4 - Perguntas extraídas do checklist para identificar a percepção do executivo de assuntos portuários da SC Par

Com base nas entrevistas, teve início o processo de estruturação do modelo.

\subsubsection{Elementos Primários de Avaliação, Conceitos e Áreas de Preocupação}

As entrevistas feitas com base no questionário foram gravadas para que, em seguida, os facilitadores pudessem identificar as características básicas que impactassem nos valores da organização, que são os Elementos Primários de Avaliação (EPAs). Ensslin et al. (2010) citam que, nessa etapa, deve-se identificar o maior número possível de EPAs. Depois de analisar as entrevistas, foi possível identificar 37 EPAS citados no processo de interação entre decisor e facilitadores. Tendo em vista que os EPAs ainda são ideias iniciais, é recomendado desenvolvêlos a fim de identificar os conceitos que podem ser extraídos e que representam a 
expansão de conhecimento acerca do contexto estudado (Eden, 1988; Ensslin, Montibeller, \& Noronha, 2001).

Os conceitos são desenvolvidos com base em duas direções de preferências: o primeiro, polo presente, diz respeito ao desejo do decisor de acordo com suas preferências em relação ao objetivo; e o segundo corresponde às consequências que o decisor deseja evitar, chamado de polo psicológico oposto. Ambos são separados pelo uso de reticências (...), que é lido como "é preferível a" ou "ao invés de" (Ensslin et al., 2010). A Figura 5 representa um recorte de alguns EPAs e seus respectivos conceitos desenvolvidos.

\section{EPAs}

\begin{tabular}{|c|c|c|c|c|c|}
\hline 21 & $\begin{array}{l}\text { Monitoramento } \\
\text { Periódico }\end{array}$ & 30 & $\begin{array}{l}\text { Manter a periodicidade de } \\
\text { monitoramento dos portos. }\end{array}$ & $(\ldots)$ & $\begin{array}{l}\text { Perder o controle das atividades } \\
\text { realizadas nos portos. }\end{array}$ \\
\hline 22 & $\begin{array}{l}\text { Relacionamento } \\
\text { entre diretorias }\end{array}$ & 31 & $\begin{array}{l}\text { Manter um bom } \\
\text { relacionamento entre } \\
\text { diretorias e holding. }\end{array}$ & $(\ldots)$ & $\begin{array}{l}\text { Desconhecer os problemas reais } \\
\text { dos portos. }\end{array}$ \\
\hline 23 & $\begin{array}{l}\text { Parametrizar } \\
\text { exigências }\end{array}$ & 32 & $\begin{array}{l}\text { Nivelar as exigências aos } \\
\text { portos. }\end{array}$ & $(\ldots)$ & $\begin{array}{l}\text { Utilizar diferentes padrões de } \\
\text { cobrança, comprometendo o } \\
\text { relacionamento. }\end{array}$ \\
\hline \multirow[b]{2}{*}{24} & \multirow{2}{*}{$\begin{array}{l}\text { Acompanhamento } \\
\text { de políticas de } \\
\text { gestão }\end{array}$} & 33 & $\begin{array}{l}\text { Estabelecer uma rotina de } \\
\text { acompanhamentos. }\end{array}$ & $(\ldots)$ & $\begin{array}{l}\text { Deixar o porto livre para decidir o } \\
\text { que apresentar. }\end{array}$ \\
\hline & & 55 & $\begin{array}{l}\text { Estabelecer indicadores } \\
\text { de monitoramento. }\end{array}$ & $(\ldots)$ & $\begin{array}{l}\text { Ter falhas de monitoramento em } \\
\text { decorrência da falta de } \\
\text { indicadores estabelecidos. }\end{array}$ \\
\hline 25 & $\begin{array}{l}\text { Otimização de } \\
\text { recursos }\end{array}$ & 34 & $\begin{array}{l}\text { Desenvolver meios de } \\
\text { otimizar recursos. }\end{array}$ & $(\ldots)$ & $\begin{array}{l}\text { Deixar de investir em opções } \\
\text { potenciais em decorrência da } \\
\text { distribuição de recursos } \\
\text { indevidos. }\end{array}$ \\
\hline 27 & $\begin{array}{l}\text { Limite de } \\
\text { decisões }\end{array}$ & 36 & $\begin{array}{l}\text { Estabelecer até que ponto } \\
\text { as decisões são tomadas } \\
\text { pela holding. }\end{array}$ & $(\ldots)$ & $\begin{array}{l}\text { Atribuir decisões de nível } \\
\text { estratégico aos portos por falta } \\
\text { de limite de decisões. }\end{array}$ \\
\hline 28 & $\begin{array}{l}\text { Ações } \\
\text { Desenvolvidas }\end{array}$ & 37 & $\begin{array}{l}\text { Acompanhar ações } \\
\text { desenvolvidas pelos } \\
\text { portos. }\end{array}$ & $(\ldots)$ & $\begin{array}{l}\text { Desconhecer o funcionamento } \\
\text { da estrutura portuária. }\end{array}$ \\
\hline 29 & $\begin{array}{l}\text { Periodicidade de } \\
\text { apresentação das } \\
\text { demonstrações }\end{array}$ & 38 & $\begin{array}{l}\text { Disponibilidade das } \\
\text { informações de interesse } \\
\text { da holding em tempo real. }\end{array}$ & $(\ldots)$ & $\begin{array}{l}\text { Ter acompanhamento com } \\
\text { grandes intervalos que dificultam } \\
\text { a identificação da situação dos } \\
\text { portos. }\end{array}$ \\
\hline
\end{tabular}

Figura 5 - Recorte dos EPAs identificados e conceitos resultantes

A seguir, os conceitos foram agrupados por área de interesse, gerando quatro áreas de preocupação/dimensão, permitindo uma visualização mais clara das preocupações principais dos decisores (Rodrigues et al., 2018). A Figura 6 evidencia as áreas de preocupação/dimensões encontradas, e os números representam os conceitos correspondentes a cada uma delas. 


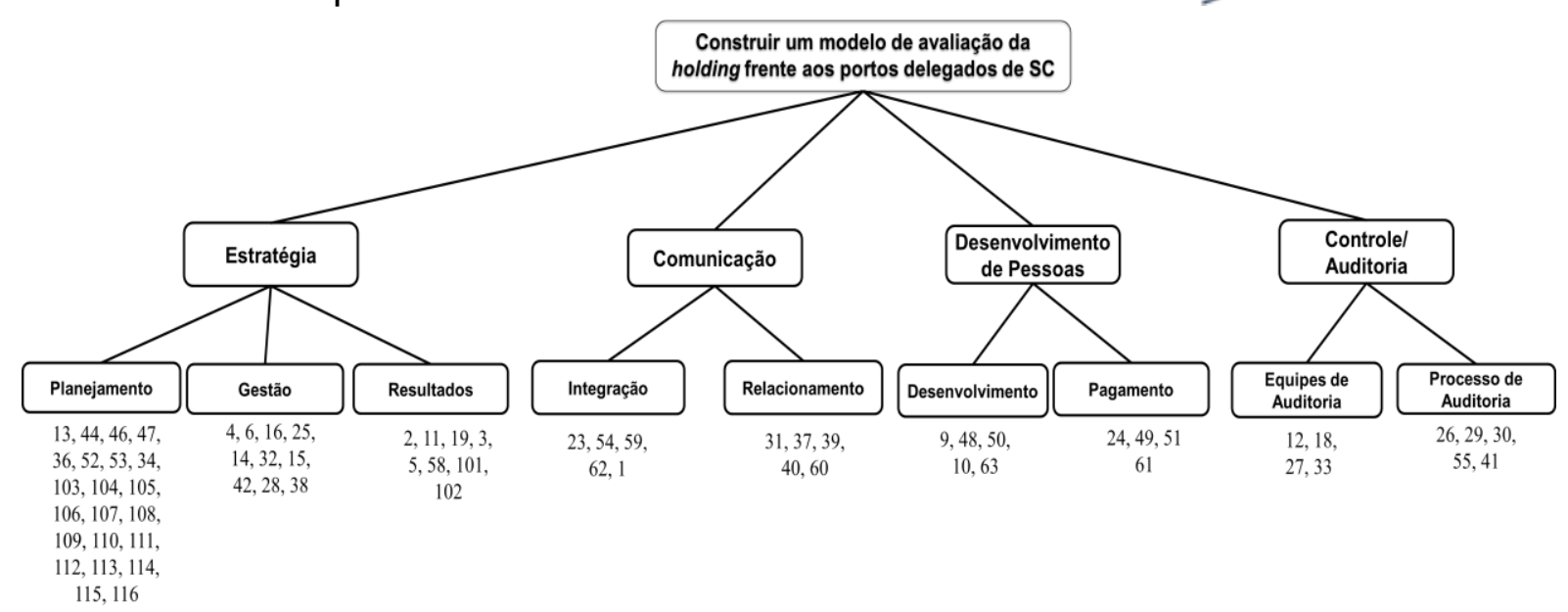

Figura 6 - Identificação das áreas de preocupação do modelo de AD da holding SC Par

Cada área é formada por candidatos a Pontos de Vista Fundamentais. Assim, nessa etapa, verifica-se se esses Pontos de Vista Fundamentais (PVFs) atendem às propriedades de essencialidade e suficiência. Em caso positivo, o conjunto passa a ser denominado como Família de Pontos de Vista Fundamental (FPVFs).

\subsubsection{Mapas Meios-Fins, Estrutura Hierárquica de Valor e Descritores}

A seguir, visando expandir o conhecimento para permitir operacionalizar os PVFs, os conceitos associados a cada um são organizados em relações de hierarquia e influência entre os conceitos (Eden, 1988; Ensslin et al., 2010). Essas estruturas de relações meios-fins denominam-se Mapas Cognitivos (Ensslin, Dutra, \& Ensslin, 2000; Ensslin, Montibeller, \& Noronha, 2001). Dada sua expansão de entendimento, surgem novos conceitos.

Para melhorar seu entendimento, os mapas meios-fins são agrupados e formam clusters e subclusters. Cada uma dessas estruturas recebe uma denominação associada à sua preocupação. Dada a forma como os mapas são construídos, os clusters são independentes entre si. Com o propósito de permitir a evolução do processo de construção de conhecimento, a estrutura de clusters é transferida para uma Estrutura Hierárquica de Valor (EHV), na qual cada cluster representará um PVF, e cada subcluster, um Ponto de Vista Elementar. A Figura 7 ilustra o Ponto de Vista Fundamental (PVF) "Planejamento", vinculado à área de preocupação/dimensão "Estratégia". 


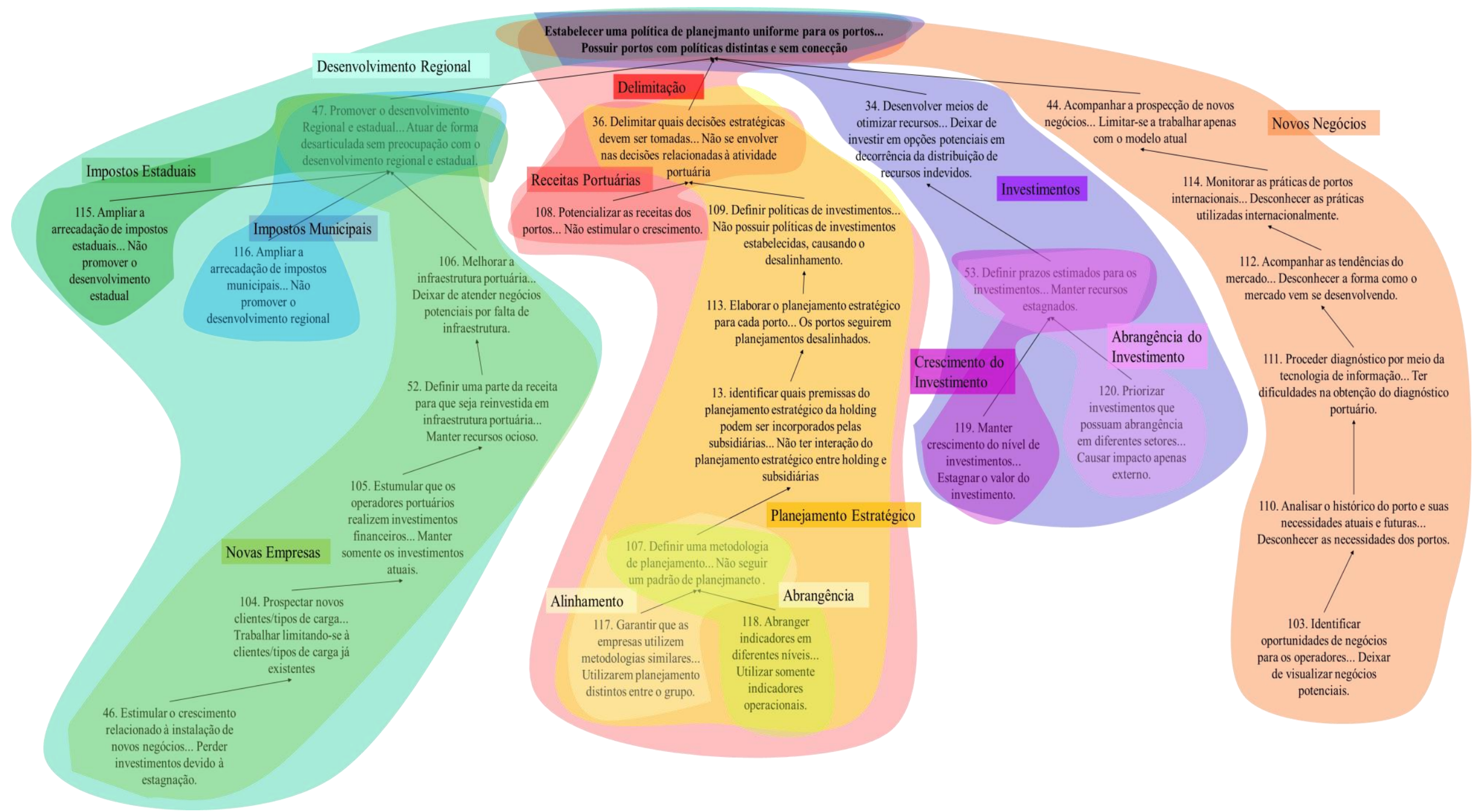

Figura 7 - Identificação dos clusters e subclusters do PVF "Planejamento" 
Dessa forma, com base nos cluster e subclusters identificados, é possível apresentar, na Figura 8, a Estrutura Hierárquica de Valor do PVF "Planejamento".

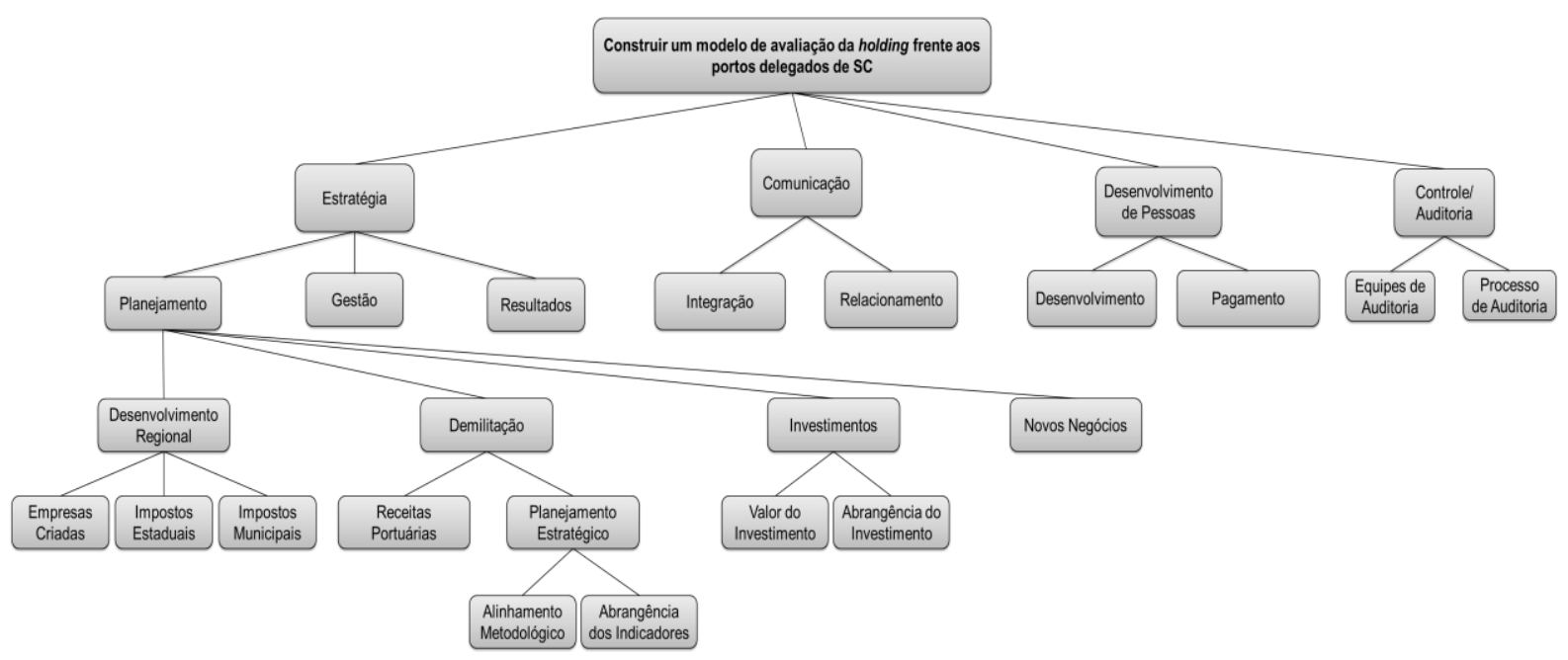

Figura 5 - Estrutura Hierárquica de Valor do PVF "Planejamento"

Cumpre salientar que os aspectos localizados na parte inferior da Figura 7 se constituem como objetivos necessários de serem avaliados, denominados, na metodologia MCDA-C, de Pontos de Vista Elementar (PVE). Ou seja, a holding, quanto à estratégia de planejamento para o desenvolvimento regional, será avaliada em relação às empresas criadas e aos impostos estaduais e municipais gerados. Assim, nesse momento, sabe-se o 'que' será avaliado.

Uma vez identificada a EHV, esta necessita ser operacionalizada, ou seja, informar qual o possível desempenho que será considerado pelo gestor da holding em cada um dos aspectos (PVE). Para tal, é identificada uma unidade de medida e é construída uma escala ordinal, denominada, na metodologia MCDA-C, descritor. O descritor é composto por um conjunto de níveis de ocorrências de desempenho, aceitos pelo decisor, ordenados por ordem de preferência (Ensslin, Dutra, \& Ensslin, 2000). Nesse conjunto, o decisor identifica os níveis de referência (ou níveis âncoras), denominados Nível Bom e Nível Neutro, que dividem a escala ordinal em regiões que sinalizam os níveis considerados com desempenho de excelência, competitivo e comprometedor (Ensslin et al., 2018; Longaray et al., 2018; Matos, Valmorbida, \& Ensslin, 2018). A Figura 6 demonstra a EHV do PVF "Planejamento", com seus respectivos descritores (unidade de medida e escala ordinal), isto é, o modelo qualitativo está construído. Na Figura 8, é apresentado o perfil de desempenho da SC Par. 


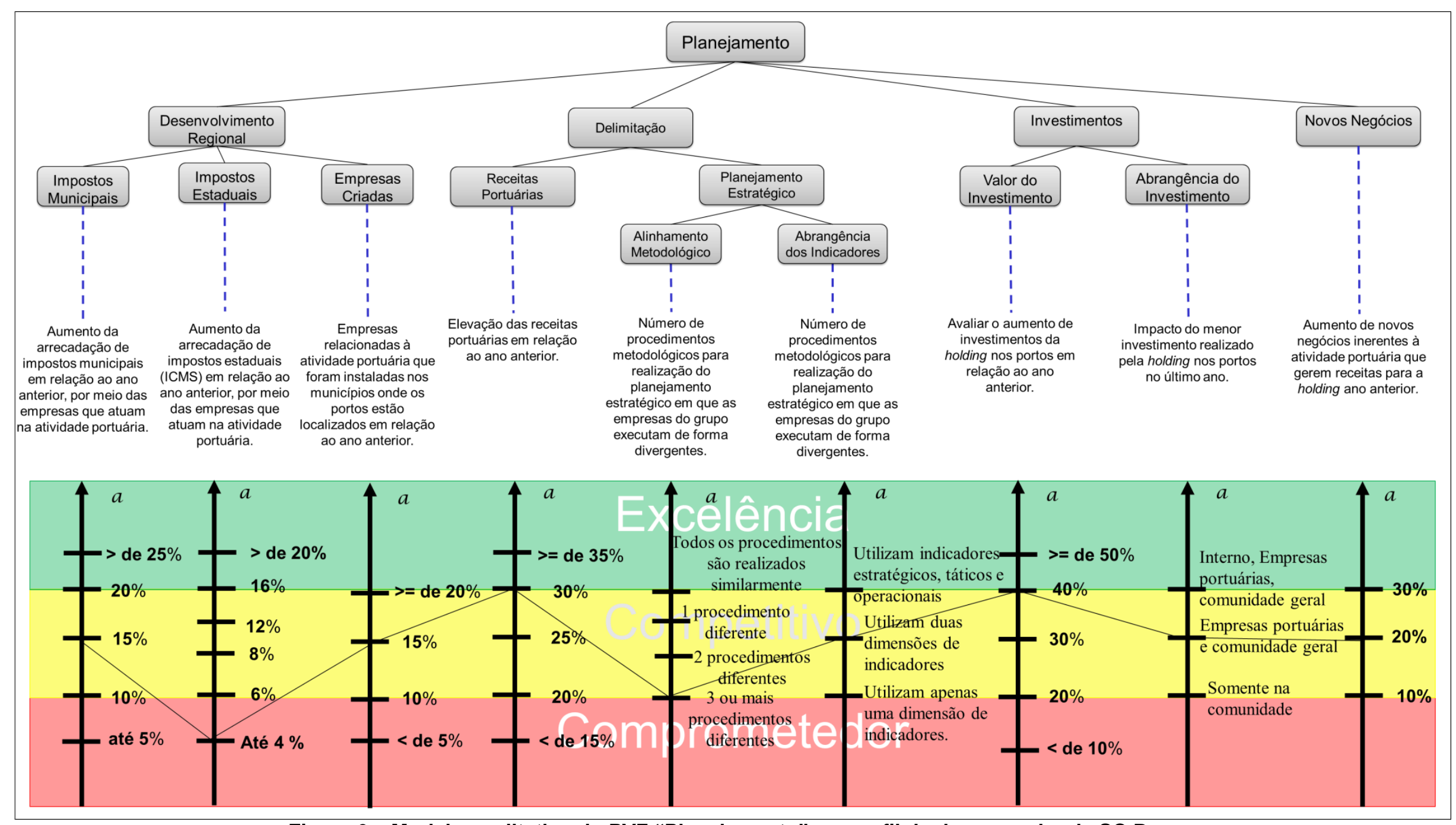

Figura 6 - Modelo qualitativo do PVF "Planejamento" e o perfil de desempenho da SC Par 
A construção dos descritores encerra a Fase de Estruturação do modelo e evidencia todo o conhecimento gerado no decisor, representado nesse modelo qualitativo. Para expandir o conhecimento, é necessário agora transformá-lo em cardinal, o que será feito na Fase de Avaliação.

\subsection{Fase de Avaliação}

De acordo com Ensslin et al. (2010), a Fase de Avaliação incorpora dois tipos de conhecimentos: o primeiro, ao transformar as escalas ordinais (qualitativas) em cardinais (quantitativas), permitindo conhecer a diferença de atratividade entre os níveis dos descritores; e o segundo, ao estabelecer as taxas de compensação, o que permite conhecer as contribuições relativas de cada critério. Essas duas informações permitem uma avaliação numérica (quantitativa) em cada aspecto, ponto de vista, área de preocupação e global (por meio do perfil de desempenho das ações).

\subsubsection{Função de Valor, taxas de compensação e perfil do modelo Global}

Para realizar essa transformação de escalas ordinais, ou descritores, em escalas cardinais, ou escalas de intervalo, foi utilizado o software Macbeth (Bana e Costa \& Vansnick, 1995), com base na diferença de atratividade entre dois níveis do descritor (Longaray et al., 2018), representando os juízos de preferência do decisor. Dessa forma, todos os descritores do modelo foram transformados em escalas cardinais. Na Figura 8, é apresentada uma transformação da escala ordinal para a escala cardinal, com o auxílio do software utilizado.
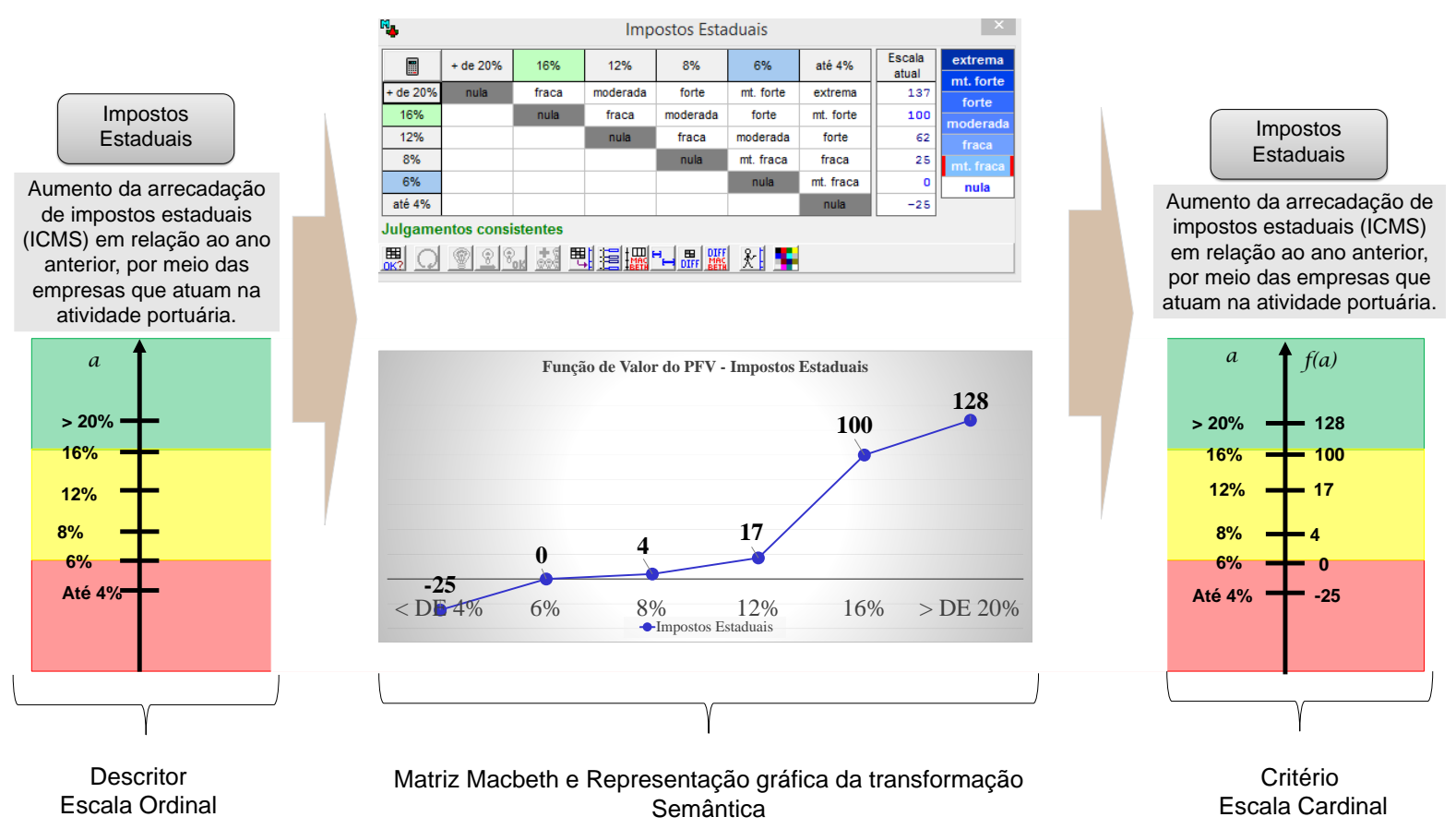

Figura 7 - Exemplo da transformação do descritor em função de valor

O procedimento descrito na Figura 7 foi feito para cada um dos descritores do Ponto de Vista Fundamental "Planejamento", a fim de obter a diferença de atratividade entre os níveis dos descritores. A Figura 10 apresenta a EHV para o PVF "Planejamento", composta pelas escalas ordinais e cardinais obtidas por meio do software Macbeth. 


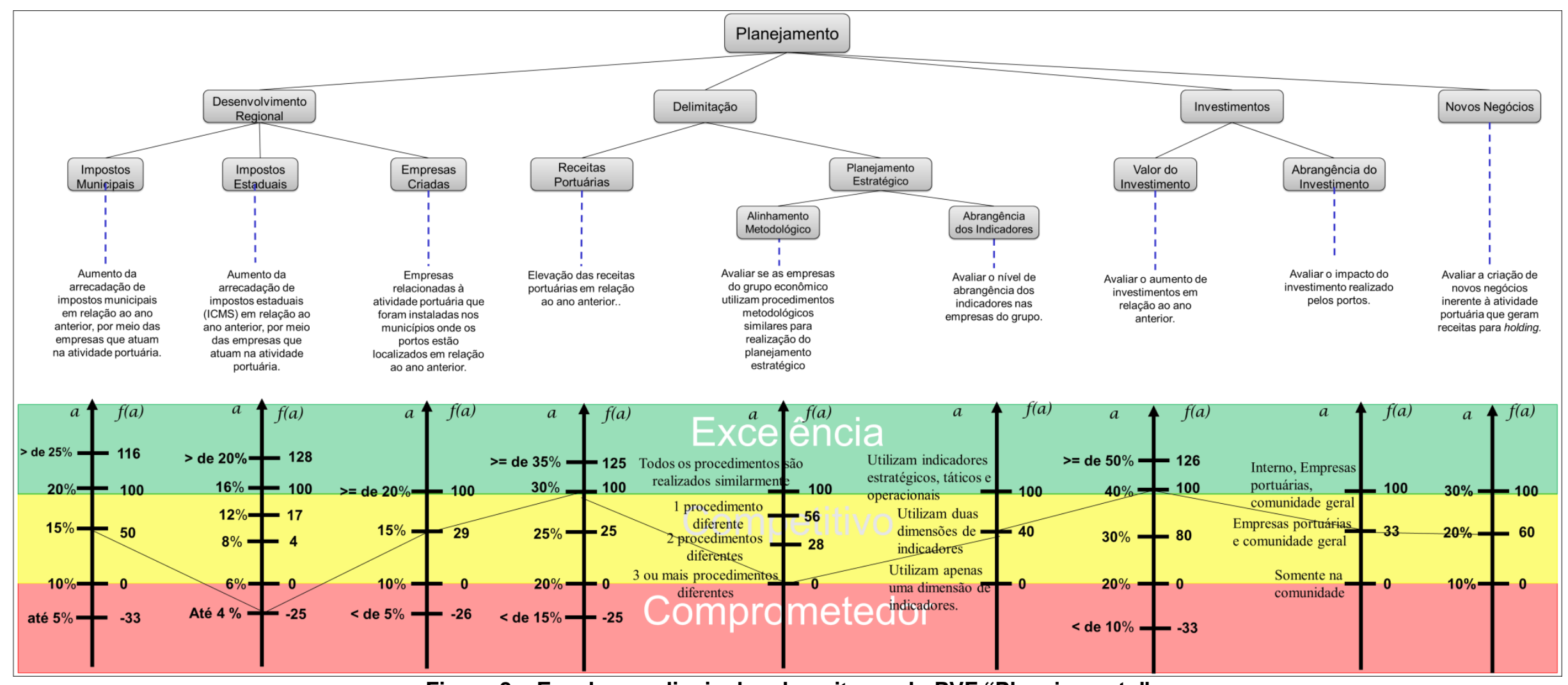

Figura 8 - Escalas cardinais dos descritores do PVF "Planejamento" 
Com as escalas cardinais concluídas, tem-se formado um critério ou indicador de desempenho. Nesse momento, o decisor já detém de um entendimento que lhe permite a mensuração cardinal local de forma operacional, entretanto ainda não é possível verificar os aspectos estratégicos (PVF), tampouco os aspectos táticos (PVE intermediários) (Ensslin et al., 2010). Para isso, são definidas as taxas de compensação, que representam a contribuição do critério do ponto de vista superior quando uma alternativa tem seu desempenho melhorado do Nível Neutro para o Nível Bom, permitindo a avaliação da holding de forma global.

A metodologia MCDA-C se vale do Modelo de Agregação a um Critério Único de Síntese (Roy, 1985) e este requer que os critérios que formam o modelo sejam, de preferência, cardinalmente independentes, isto é, que a atratividade de passar do nível de referência inferior para o de referência superior em cada critério não sofra em sua intensidade quando de mudanças do desempenho em outros critérios. $O$ processo para realizar o teste de independência preferencial cardinal é feito em três etapas: (i) determinação das alternativas associadas à atratividade de passar do nível de referência inferior para o de referência superior; (ii) ordenação das alternativas; e (iii) determinação das taxas. Dessa forma, para cada critério, foi realizada a determinação das alternativas potenciais associadas à contribuição de passagem do Nível Neutro para o Nível Bom, para todos os critérios em que se pretendia determinar as taxas, bem como uma ação de referência (fictícia) cujo desempenho, em todos os pontos de vista, se encontrava no Nível Neutro. Em seguida, para ordenação das alternativas, foi utilizada a Matriz de Roberts (1979). Para as alternativas ordenadas, foi solicitado ao decisor informar a diferença de atratividade entre elas e com a ajuda do software Macbeth, foi então realizado. Foi feito o mesmo processo de construção das escalas cardinais para identificar as taxas de compensação. A Figura 9 demonstra o processo realizado para o PVE "Desenvolvimento Regional".
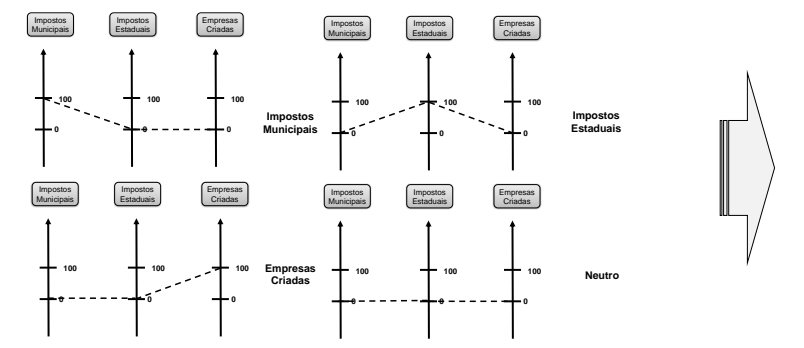

\begin{tabular}{|c|c|c|c|c|c|}
\hline \multicolumn{6}{|c|}{ Matriz de Roberts - Desenvolvimento Regional } \\
\hline & $\begin{array}{l}\text { Impostos } \\
\text { Municipais }\end{array}$ & \begin{tabular}{|l} 
Impostos \\
Estaduais
\end{tabular} & $\begin{array}{c}\text { Empresas } \\
\text { Criadas }\end{array}$ & Nulo & Total \\
\hline \begin{tabular}{|c|} 
Impostos \\
Municipais
\end{tabular} & & 0 & 0 & 1 & 1 \\
\hline $\begin{array}{l}\text { Impostos } \\
\text { Estaduais }\end{array}$ & 1 & & 0 & 1 & 2 \\
\hline $\begin{array}{c}\text { Empresas } \\
\text { Criadas }\end{array}$ & 1 & 1 & & 1 & 3 \\
\hline Nulo & 0 & 0 & 0 & & 0 \\
\hline
\end{tabular}
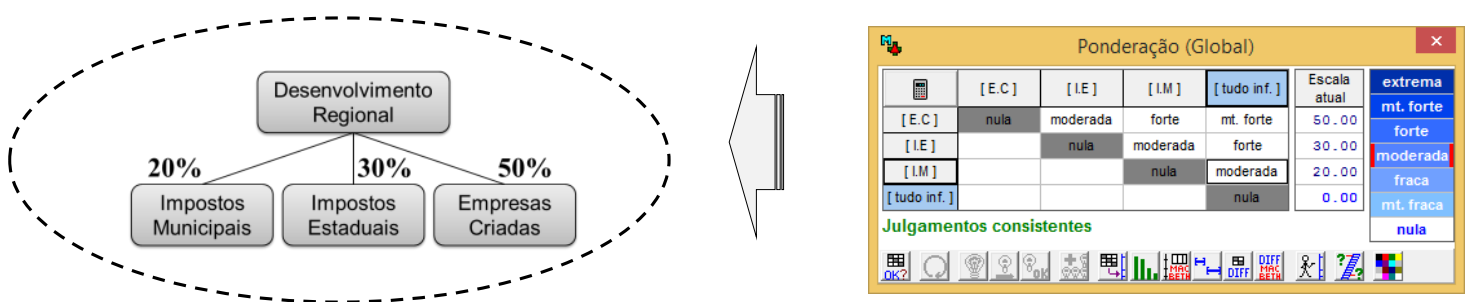

Figura 9 - Processo de identificação das Taxas de Compensação para o PVE "Desenvolvimento Regional"

Destaca-se que o processo apresentado foi feito para todos os PVEs, para identificar a contribuição de cada um deles no PVF "Planejamento". 


\subsubsection{Avaliação Global, Perfil de Impacto Atual e Análise de Sensibilidade}

Há de se considerar ainda que pode haver incertezas no julgamento do decisor no desenvolvimento do modelo Multicritério e, portanto, optou-se por verificar a consistência das informações por meio do teste de sensibilidade, realizado com o apoio do software HIVIEW. Com isso, verificou-se que o modelo construído é robusto e estável, podendo-se concluir a Fase de Avaliação do modelo.

A Avaliação Global corresponde à agregação aditiva dos modelos de cada PVF. Nesse caso, como o modelo apresentado evidencia apenas um PVF (Planejamento), a equação do modelo apresenta-se na seção 2.2, e o desempenho da holding SC Par é evidenciado na cor vermelha.

$$
\begin{gathered}
V_{\text {planejamento }}(a)= \\
0,40 \times\left\{0,20 \times\left(\begin{array}{c}
116 \\
100 \\
50 \\
0 \\
-33
\end{array}\right)+0,30 \times\left(\begin{array}{c}
128 \\
100 \\
17 \\
4 \\
0 \\
-25
\end{array}\right)+0,50 \times\left(\begin{array}{c}
100 \\
29 \\
0 \\
-26
\end{array}\right)\right]+ \\
\left.0,60 \times\left[\begin{array}{c}
125 \\
100 \\
25 \\
0 \\
-25
\end{array}\right]+0,40 \times\left[0,40 \times\left(\begin{array}{c}
100 \\
56 \\
28 \\
0
\end{array}\right)+0,60 \times\left(\begin{array}{c}
100 \\
40 \\
0
\end{array}\right)\right]\right\}+ \\
\left.0,20\left[\begin{array}{c}
126 \\
100 \\
80 \\
0
\end{array}\right)+0,40 \times\left(\begin{array}{c}
100 \\
33 \\
0
\end{array}\right)\right]+ \\
0,10 \times\left(\begin{array}{c}
100 \\
60 \\
0
\end{array}\right)
\end{gathered}
$$

Figura 10 - Equação para avaliação global do PVF "Planejamento" e desempenho da SC Par

A avaliação, no nível tático da holding SC Par no PVF "Planejamento", com o perfil identificado, resultou em uma pontuação de 53 pontos, em uma escala de 0 a 100 pontos, evidenciando um desempenho em nível competitivo, conforme a Figura 11. 


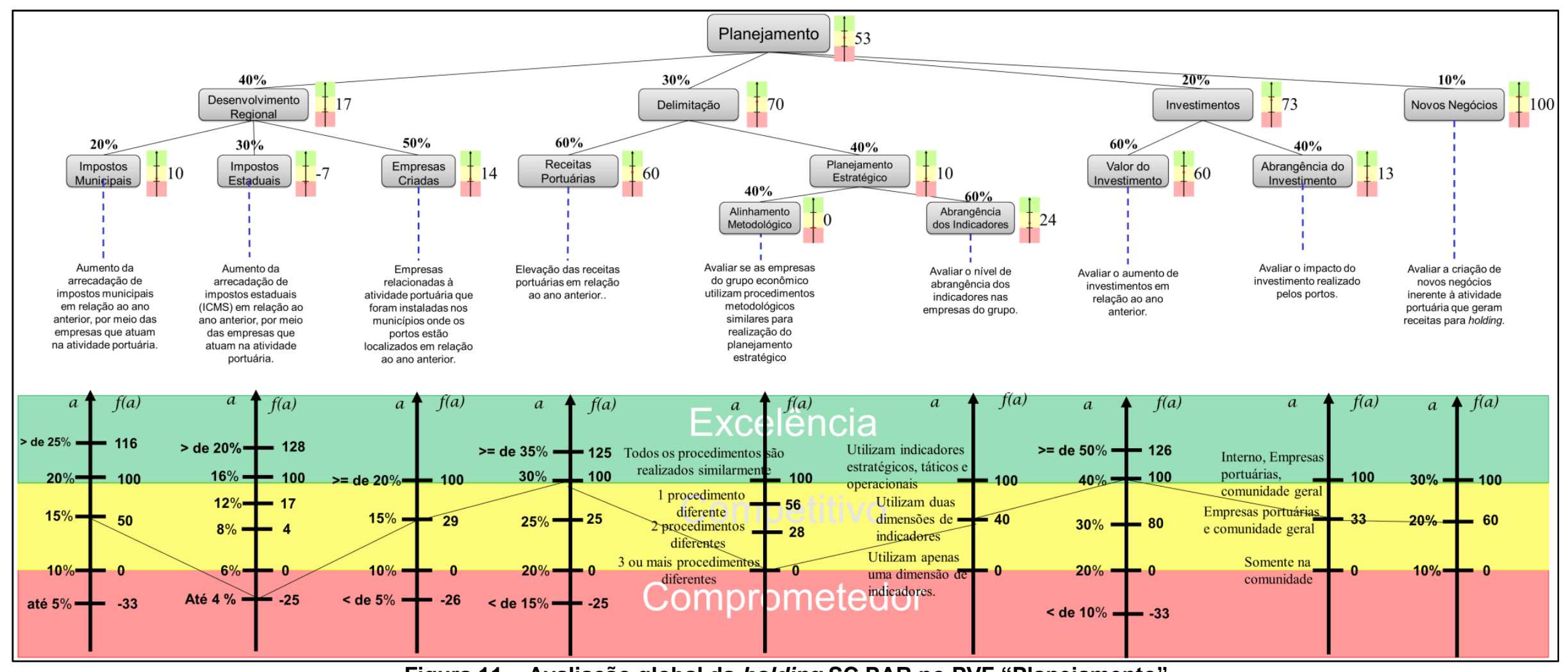

Figura 11 - Avaliação global da holding SC PAR no PVF "Planejamento" 
VI CIDESPORT/2019

Congresso Internacional

de Desempenho Portuário

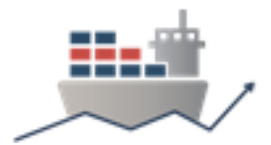

Cumpre observar que, embora o desempenho global da holding SC Par, no nível tático do PVF "Planejamento", se encontre em nível competitivo, se constata, na Figura 13, o desempenho comprometedor da holding no aspecto (subPVE) "Impostos Estaduais" de "Desenvolvimento Regional"; e quase comprometor no aspecto (subPVE) "Alinhamento Metodológico" do "Planejamento Estratégico". Dessa forma, a título de gestão, recomenda-se uma atuação proativa do decisor, com base nas informações propiciadas pelo modelo construído. Isso será explorado na Fase de Recomendações.

\subsection{Fase de Recomendações}

A Fase de Recomendações auxilia não só o decisor a identificar ações que possam ser tomadas para melhorar o statu quo (desempenho atual), como também a entender as consequências, em termos de pontuação, dessas ações recomendadas nos objetivos estratégicos, caso sejam implementadas (Ensslin et al., 2018). Contudo, essa etapa não objetiva informar o que fazer, e sim auxiliar a compreender as ações e suas consequências.

Com isso, inicia-se o processo identificando no qual a holding SC Par apresenta desempenho em nível comprometedor ou neutro. $O$ desempenho comprometodor da holding está no aspecto (subPVE) "Impostos Estatuais" de "Desenvolvimento Regional". Na sequência, verificam-se quais aspectos apresentam maior taxa de contribuição no PVF "Planejamento". Constata-se que é o PVE "Empresas Criadas", por contribuir com $20 \%(0,50$ X 0,40). Assim, será demonstado o processo de geração de ações de recomendação para esses dois subPVEs. As Figuras 14 e 15, evidenciam as ações de melhoria que foram propostas. Destaca-se, ainda, que, dentre as ações apresentadas, algumas não necessitam de desembolso financeiro direto.

\begin{tabular}{|c|c|}
\hline Descritor & Ação \\
\hline 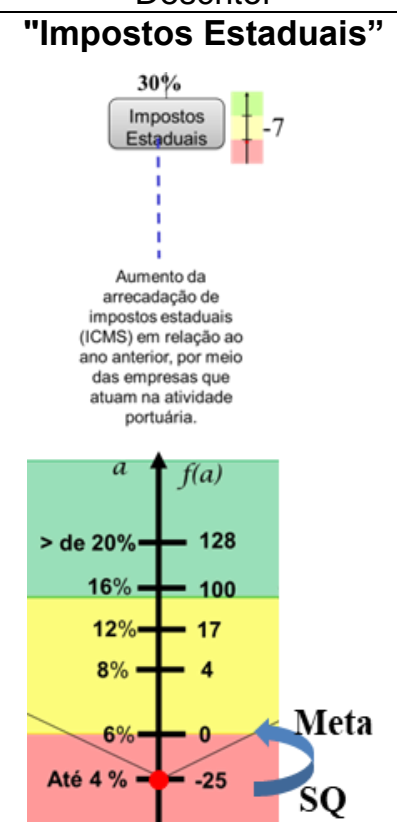 & $\begin{array}{l}\text { Ações propostas: } \\
\text { - Divulgar informações sobre as ações do estado de Santa } \\
\text { Catarina para o combate aos crimes contra a ordem tributária aos } \\
\text { atores envolvidos com a atividade portuária. } \\
\text { - Buscar apoio da Secretaria de Estado da Fazenda para } \\
\text { aumentar o efetivo de agentes que executem as atividades de } \\
\text { fiscalização nos portos ou a frequência de amostragem de cargas } \\
\text { ingressantes nos portos. } \\
\text { - Prover estrutura adequada aos agentes fiscalizadores para que } \\
\text { possam desempenhar as ações necessárias de controle e } \\
\text { fiscalização das cargas ingressantes no Estado. } \\
\text { - Realizar operações conjuntas com os portos subsidiários e a } \\
\text { Secretaria de Estado da Fazenda para a fiscalização das cargas } \\
\text { movimentadas, visando à mitigação da sonegação de impostos. } \\
\text { - Promover campanhas de concientização quanto às vantagens } \\
\text { do pagamento de impostos e das empresas se manterem } \\
\text { regulares perante o fisco estadual. } \\
\text { - Analisar as vantagens e/ou desvantagens da concessão de } \\
\text { subsídios para apoiar o desenvolvimento das empresas e o } \\
\text { possível aumento do volume de impostos arrecadados. }\end{array}$ \\
\hline & ação \\
\hline
\end{tabular}


VI CIDESPORT/2019

Congresso Internacional

de Desempenho Portuário

\begin{tabular}{|c|c|}
\hline Responsável & $\begin{array}{ll}\text { - } & \text { Executivo de Assuntos Portuários da SC } \\
& \text { Par } \\
\text { - Áreas jurídica e financeira da SC Par } \\
\text { - Equipe de comunicação da SC Par }\end{array}$ \\
\hline Data de início & O mais breve possível \\
\hline Data de término & 6 meses após o início \\
\hline Frequência do acompanhamento & Mensal \\
\hline Responsável por acompanhar & Executivo de assuntos portuários \\
\hline Impacto no descritor & $\begin{array}{l}\text { Nível Atual: N6 (Pontuação: -25) } \\
\text { Nível meta: N5 (Pontuação: 0) }\end{array}$ \\
\hline Impacto no PVE Desenvolvimento Regional & +8 pontos \\
\hline Impacto no PVF Planejamento & +3 pontos \\
\hline
\end{tabular}

Figura 14 - Ações recomendadas para a holding a fim de melhorar seu desempenho no subPVE "Impostos Estaduais"

\begin{tabular}{|c|c|c|}
\hline Descritor & \multirow{2}{*}{\multicolumn{2}{|c|}{$\begin{array}{l}\text { Ação } \\
\text { Ações propostas: } \\
\text { - Pleitear, com os governos municipais, que se desenvolvam } \\
\text { ações de incentivo à abertura de empresas relacionadas à } \\
\text { atividade portuária. } \\
\text { - Investir em novos tipos de negócios para que os portos possam } \\
\text { receber e operar outros tipos de cargas de modo que aumente a } \\
\text { demanda por novas empresas. } \\
\text { - Desenvolver um canal de comunicação para os portos auxiliarem } \\
\text { os stakeholders quanto às particularidades do setor portuário e } \\
\text { ações necessárias para a abertura do negócio, visando ao } \\
\text { incentivo a novas empresas no município. } \\
\text { - Potencializar a atividade logística regional estimulando o } \\
\text { desenvolvimento de negócios vinculados ao apoio logístico da } \\
\text { atividade portuária. }\end{array}$}} \\
\hline 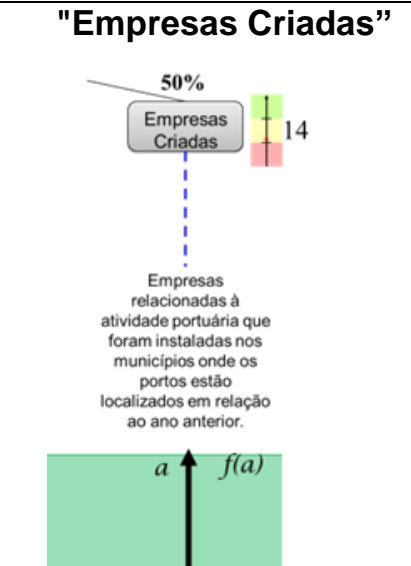 & & \\
\hline \multicolumn{2}{|l|}{ Resultado Esperado } & $\begin{array}{l}\text { Aumento do número de empresas } \\
\text { relacionadas à atividade portuária, instaladas } \\
\text { nos municípios onde os portos estão } \\
\text { localizados em relação ao ano anterior de }<\text { de } \\
15 \% \text { para >= DE } 20 \% \text {. }\end{array}$ \\
\hline \multicolumn{2}{|l|}{ Responsável } & $\begin{array}{l}\text { - } \quad \text { Diretor de assuntos portuários da SC Par } \\
\text { Equipe técnica e de comunicação da SC } \\
\text { Par }\end{array}$ \\
\hline \multicolumn{2}{|l|}{ Data de início } & O mais breve possivel \\
\hline \multicolumn{2}{|l|}{ Data de término } & 6 meses -12 meses \\
\hline \multicolumn{2}{|c|}{ Frequência do acompanhamento } & Mensal \\
\hline \multicolumn{2}{|c|}{ Responsável por acompanhar } & Executivo de assuntos portuários \\
\hline \multicolumn{2}{|l|}{ Impacto no descritor } & Nível Atual: N2 (Pontuação: 29) \\
\hline
\end{tabular}


VI CIDESPORT/2019

Congresso Internacional

de Desempenho Portuário

\begin{tabular}{|l|l|}
\hline & Nível meta: N1 (Pontuação: 100) \\
\hline Impacto no PVE Desenvolvimento Regional & +28 pontos \\
\hline Impacto no PVF Planejamento & +14 pontos \\
\hline
\end{tabular}

Figura 15 - Ações Recomendadas para a holding a fim de melhorar seu desempenho no subPVE "Empresas Criadas"

A efetiva implementação apenas dessas duas ações de propostas possibilita à holding melhorar seu desempenho em 17 pontos. Ou seja, o desempenho que atualmente se encontra com 53 pontos tem a potencialidade de atingir 70 pontos. Ressalta-se que, após a implementação, deve haver continuamente o monitoramento dos indicadores e atualização de suas escalas sempre que necessário, formando um ciclo de melhoria contínua e com foco nos resultados (Matos et al., 2019).

\subsection{Discussão dos Resultados}

Com base no modelo construído, observou-se que há preocupação crescente com o desenvolvimento portuário, compactuando com estudos propostos ao longo do tempo (Ngoc \& Moon, 2011; Pessanha et al., 2013) ao apontarem que o setor portuário representa um elo importante para o desenvolvimento da economia mundial.

O modelo desenvolvido com base na percepção do executivo de assuntos portuários da SC Par permitiu a ele esclarecer os aspectos, representando a holding, considerados como essencias para à gestão das atividades de planejamento portuárias da SC Par, mostrando a escala para mensurar seu sucesso, evidenciando o desempenho atual, bem como permitindo fixar a meta em função de suas expectativas. Esse conhecimento permitiu a geração de ações para aperfeiçoar a performance da holding daqueles aspectos que ela apresentou estar aquém da expectativa.

Nesse caso, especialmente em 2019, com a nova administração do Estado, os gestores têm buscado exercer uma atividade de gestão que influencia os setores onde ela atua. Dessa forma, a utilização do modelo proposto possibilita mensurar o quanto se está impactando frente aos negócios de suas subsidiárias, principalmente com relação ao setor portuário. Desse modo, algumas ações começaram a ser desenvolvidas já no início de 2019, buscando mais envolvimento da holding com os portos no processo de gestão. Randrianarisoa e Zhang (2019) evidenciaram, em seu estudo, os desafios que constituem a atividade portuária quando se trata da realização de investimentos, intensificado pela complexidade que envolve esse setor, consonantes com o que se percebe na situação estudada.

Cumpre salientar que as ações de melhoria propostas objetivam melhorar o desempenho organizacional da holding, bem como promover o desenvolvimento regional, buscando parcerias com os governos estadual e municipal, a fim de estreitar os laços que visam minimizar os índices de sonegação fiscal e, concomitantemente, incentivar a abertura de novos negócios relacionados à atividade portuária.

Nota-se que os melhores desempenhos da holding se encontram nos indicadores "Receitas Portuárias" e "Valor do Investimento", demonstrando que há uma preocupação por parte dos gestores em aplicar recursos nas subsidiárias a fim de melhorar suas estruturas, impactando a expansão da capacidade de armazenamento e negociação. Como resultado, há o aumento de receitas, corroborando as afirmações encontradas na literatura que apontam o aumento da eficiência com a expansão do armazenamento (Li, Liu, Leung, \& Lai, 2004; Ngoc \& Moon, 2011). 
VI CIDESPORT/2019

Congresso Internacional

de Desempenho Portuário

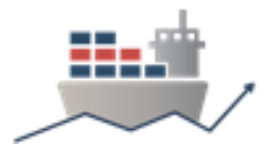

Percebeu-se, porém, que a atenção da literatura vem sendo destinada à geração de informações da Contabilidade interna a respeito do desempenho das unidades subsidiárias, com foco no processo operacional (Blackwell, Brickley, \& Weisback, 1994), dificultando a comparação de resultados. Nesse sentido, os achados desse estudo também proporcionam contribuições teóricas elencadas segundo os critérios descritos por Whetten (1989) e apresentadas na Figura 16.

\begin{tabular}{|c|l|}
\hline $\begin{array}{c}\text { Contribuição } \\
\text { Teórica }\end{array}$ & \multicolumn{1}{|c|}{ Descrição } \\
\hline O quê? & $\begin{array}{l}\text { Construção de um modelo que permita a avaliação da situação atual de } \\
\text { uma holding portuária, perante suas subsidiárias, em um ambiente } \\
\text { complexo, em que predomina a incerteza. }\end{array}$ \\
\hline Como? & $\begin{array}{l}\text { Por meio da análise da literatura realizada com o auxílio da ferramenta } \\
\text { Proknow-C, identificaram-se oportunidades de pesquisa e de interesse dos } \\
\text { autores (Matos, Valmorbida, \& Ensslin, 2018; Staedele, Ensslin, \& }\end{array}$ \\
\hline Por quê? & $\begin{array}{l}\text { Forcellini, 2019). Para suprir essa lacuna de pesquisa, utilizou-se a } \\
\text { metodologia MCDA-C, a qual, considera as particularidades do contexto } \\
\text { organizacionais e as preferências do decisor (Longaray et al., 2018). }\end{array}$ \\
\hline $\begin{array}{l}\text { Como a área portuária pública gerida por holding é escassa e carece de } \\
\text { estudos e ferramentas que considerem a percepção do decisor no } \\
\text { ambiente em que está inserida, tendo em vista que cada ambiente possui } \\
\text { suas particularidas, a construção de um modelo que avalie a situação da } \\
\text { organização frente a suas subsidiárias possibilita ao executivo de assuntos } \\
\text { portuários munir-se de informações que facilitem o processo de tomada de } \\
\text { decisões. }\end{array}$ \\
\hline
\end{tabular}

Figura 16 - Síntese das contribuições teóricas do trabalho

Fonte: Desenvolvido pelos autores (2019) com base em Whetten (1989).

\section{CONSIDERAÇÕES FINAIS}

As mudanças estruturais mundiais ocorridas a partir da década de 1990, tanto na forma, como principalmente nos volumes das transações mercantis, estabeleceram novos padrões de oportunidades para 0 desenvolvimento socioeconômico regional dos locais com acesso às rotas internacionais, como é o caso dos portos. O governo do estado de Santa Catarina, ciente da relevância dos portos como catalizadores para impulsionar o desenvolvimento da região, adicionou as atribuições da holding SC Participações e Parcerias S.A. às funções de apoiar o planejamento e a expansão dos portos do Estado. Ao assumir tais obrigações, a holding se questionou quanto à sua adequação estrutural e profissional para bem desempenhar as novas funções junto aos portos. Como subsídio a esse contexto, a presente pesquisa teve por objetivo construir um modelo de apoio à gestão das atividades portuárias da SC Par com base na percepção do executivo de assuntos portuários da holding.

A construção do conhecimento necessário, para que os facilitadores interagissem com o executivo de assuntos portuários da SC Par a fim de identificar, mensurar e integrar os elementos considerados necessários e suficientes ao contexto analisado, foi realizada por meio da intervenção do ProKnow- $C$, o qual permitiu que os facilitadores encontrassem na literatura as necessidades dos portos sob administração de holdings e mapeassem os estudos de Avaliação de Desempenho realizados em holdings. Com isso, identificou-se a lacuna existente na literatura no que tange a estudos que tratem da gestão por meio de holdings e que se limitem a aspectos operacionais dos portos, reforçando a importância de estudos que investiguem aspectos estratégicos da gestão nesses ambientes. 
VI CIDESPORT/2019

Congresso Internacional

de Desempenho Portuário

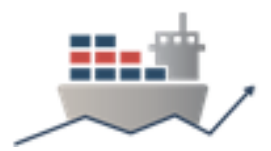

Tendo em vista a necessidade de respeitar as singularidades da organização, o reconhecimento do executivo (representando os interesses da SC Par) da necessidade de expandir seus conhecimentos quanto à interconexão das características das propriedades do contexto e seus valores, preferências, motivações e preocupações, os conflitos de interesses, o elevado número de variáveis envolvidas, foi selecionada a metodologia MCDA-C para lidar com tais ambientes decisionais.

O modelo para apoiar a gestão das atividades portuárias da SC Par foi desenvolvido com base em procedimentos, etapas e atividades da metodologia MCDA-C, identificando as seguintes áreas de preocupação: Estratégia; Comunicação; Desenvolvimento de Pessoas; e Controle/Auditoria, que foram representados por nove Pontos de Vista Fundamentais, sendo Planejamento 0 primeiro vinculado à dimensão "Estratégia" para o qual o modelo de Avaliação de Desempenho foi construído.

Para a metodologia MCDA-C, a gestão é entendida como o processo de proposição de ações de apefeiçoamento para melhoria do status quo identificado com base no conhecimento gerado quando do processo de identificação, organização, mensuração dos aspectos (critérios) considerados necessários e suficientes para avaliação do contexto, segundo a percepção do(s) decisor(es). Na seção 4.2.2Avaliação Global, Perfil de Impacto Atual e Análise de Sensibilidade, é apresentado o perfil de desempenho do statu quo e sua pontuação. O perfil de desempenho evidenciou onde a holding apresentava desempenho em níveis de execelência, competitivo e comprometedor. Para este último, foram ilustradas duas propostas de ações de aperfeiçoamento, demostrando o pleno alcance do objetivo proposto. Com a construção do modelo ad hoc Construtivista, foi possível identificar o quão preparada a SC Par se encontra em termos estratégicos para atuar na gestão portuária catarinense de forma a promover o desempenho dos portos de interesse público, evidenciando que, mesmo que haja ações em andamento, iniciadas antes da interação dos facilitadores com o decisor, o modelo proposto levantou ações de melhoria quanto à arrecadação de impostos estaduais e à criação de novas empresas relacionadas à atividade portuária, capazes de acelerar o desenvolvimento da gestão portuária e intensificar a geração de investimentos nesse setor.

Contudo, por se tratar de um estudo de caso que segue uma abordagem Construtivista, a generalização, ou replicação, desse modelo em outros contextos deve ser feita com cautela, devido às particularidades da organização objeto deste estudo. Ainda, foi operacionalizada apenas a dimensão (PVE) Planejamento, recomendando-se para próximas pesquisas a construção dos demais PVE e PVF, permitindo a avaliação global do modelo e contribuindo com ações de aperfeiçoamento que abarquem todas as áreas de preocupação apontadas pelo decisor.

\section{REFERÊNCIAS}

Agnarsson, S., Matthiasson, T., \& Giry, F. (2016). Consolidation and distribution of quota holdings in the Icelandic fisheries. Marine Policy, 72, 263-270. [HP1]

Albert, S. (2015). US bank holding companies: Structure of activities and performance through the cycles. International Review of Financial Analysis, 42, 253-269. [AD1]

Andrews, B. H., Carpentier, J. J., \& Gowen, T. L. (2001). A new approach to performance measurement and goal setting. Interfaces, 31(3), 44-54. [AD2] 
VI CIDESPORT/2019

Congresso Internacional

de Desempenho Portuário

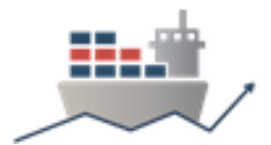

BANA E COSTA, C. A., SILVA, F. N. Concepção de uma "Boa" Alternativa de Ligação Ferroviária ao Porto de Lisboa: uma aplicação da metodologia multicritério de apoio à decisão e à negociação. Investigação Operacional, vol. 14, pp. 115-131, 1994.

Bana e Costa, C. A. \& Vansnick, J. C. (1994). MACBETH - an interactive path towards the construction of cardinal value functions, International Transactions in Operational Research, 1(4), 489-500.

Bana e Costa, C. A. \& Vansnick, J. C. (1995). Uma nova abordagem ao problema de construção de uma função de valor cardinal: MACBETH. Investigação operacional, 15(1), 15-35.

Blackwell, D. W., Brickley, J. A., \& Weisback, M. S. (1994). Accounting information and internal performance evaluation: evidence from Texas banks. Journal of Accounting and Economics, 17(3), 331-358. [AD3]

Brighi, P., \& Venturelli, V. (2014). How do income diversification, firm size and capital ratio affect performance? Evidence for bank holding companies. Applied Financial Economics, 24(21), 1375-1392. [AD4]

Chen, P. S. L., Pateman, H., \& Sakalayen, Q. (2017). The latest trend in Australian port privatisation: Drivers, processes and impacts. Research in Transportation Business \& Management, 22, 201-213. [HP2]

Chen, J., Zhang, R., \& Liu, B. (2016). The empirical study of the remuneration of port China and shipping companies listed navigation based on analysis relational gray. Theory and Application. 6, 259 - 269. [HP3]

Dutra, A., Ripoll-Feliu, V. M, Fillol, A. G., Ensslin, S. R., \& Ensslin, L. (2015). The construction of knowledge from the scientific literature about the theme seaport performance evaluation. International Journal of Productivity and Performance Management, 64(2), $243-269$.

Eden, C. (1988). Cognitive mapping. European Journal of Operational Research, 36, 01-13.

Ensslin, L., Dezem, V., Dutra, A., Ensslin, S. R., \& Somensi, K. (2017). Management support for agricultural enterprises: a case study for a fruit-producing company. International Food and Agribusiness Management Review, 20(4), 493510.

Ensslin, L.; Dutra, A. \& Ensslin, S. R. (2000). MCDA: a constructivist approach to the management of human resources at a governmental agency. International Transactions in Operational Research, 7(1), 79-100.

Ensslin, L., Ensslin, S., Dutra, A., Longaray, A., \& Dezem, V. (2018). Performance assessment model for bank client's services and business development process: a constructivist proposal. International Journal of Applied Decision Sciences, 11(1), 100-126.

Ensslin, L., Giffhorn, E., Ensslin, S. R., Petri, S. M., \& Vianna, W. B. (2010). Avaliação de Desempenho de empresas terceirizadas com o uso da metodologia Multicritério de Apoio à Decisão-Construtivista. Pesquisa Operacional, 30(1), 125152.

Ensslin, L.; Montibeller, G. \& Noronha, S. M. (2001). Apoio à decisão: metodologia para estruturação de problemas e avaliação multicritério de alternativas. Florianópolis: Insular. 
Hess, B. (2010). Evaluating the efficiency effects of industry consolidation: evidence from US interstate pipeline companies. International Journal of Energy Sector Management, 4(3), 462-481. [AD5]

Higgins, D. M., \& Toms, S. (2013). Explaining corporate success: The structure and performance of British fi rms, 1950-84. In Mapping European Corporations (pp. 93-126). Routledge. [AD6]

Hu, W. C., Lai, M. C., \& Huang, H. C. (2009). Rating the relative efficiency of financial holding companies in an emerging economy: A multiple DEA approach. Expert Systems with Applications, 36(3), 5592-5599. [AD7]

Keeney, R.L. (1992). Value focused-thinking: a path to creative decision-making. Cambridge: Harvard Univ. Press.

Li, J. A., Liu, K., Leung, S. C., \& Lai, K. K. (2004). Empty container management in a port with long-run average criterion. Mathematical and Computer Modelling, 40(12), 85-100. [HP4]

Liu, S. T. (2011). Performance measurement of Taiwan financial holding companies: An additive efficiency decomposition approach. Expert Systems with Applications, 38(5), 5674-5679. [AD8]

Longaray, A., Ensslin, L., Ensslin, S., Alves, G., Dutra, A., \& Munhoz, P. (2018). Using MCDA to evaluate the performance of the logistics process in public hospitals: the case of a Brazilian teaching hospital. International Transactions in Operational Research, 25(1), 133-156.

Lowe, A., \& Jones, A. (2004). Emergent strategy and the measurement of performance: The formulation of performance indicators at the microlevel. Organization Studies, 25(8), 1313-1337. [AD9]

Matos, L. S., Ensslin, S. R. \& Ensslin, L. (2019). A review on the Performance Measurement Systems life cycle elements. Lex Localis - Journal of Local SelfGovernment, no prelo.

Matos, L. D. S., Valmorbida, S. M. I., \& Ensslin, S. R. (2018). Gestión y evaluación de la monitorización en el sector de auditoría interna de una Universidad Federal Brasileña: Una propuesta constructivista. REICE. Revista Iberoamericana sobre Calidad, Eficacia y Cambio en Educación, 8, 76-96.

Matos, L. S., Valmorbida, S. M. I., Martins, V. A., \& Ensslin, S. R. (2019). Development of performance evaluation theme: a systematic analysis of the literature. Contextus - Revista Contemporânea de Economia e Gestão, 17(2), 6397.

Midoro, R., \& Parola, F. (2002). The effects of the market concentration in the maritime transport on the strategies of the container terminal operators. WIT Transactions on the Built Environment, 62. [HP5]

Morrison, C. (2007). Ownership and management in holding companies and the future of the Russian textile industry. Post-Communist Economies, 19(2), 167-186. [AD10]

Ngoc, A. D., \& Moon, I. K. (2011). The storage capacity expansion and space leasing for container depots. Flexible Services and Manufacturing Journal, 23(4), 364384. [HP6]

Pat Obi, C., \& Emenogu, A. (2003). Bank holding company expansion into nonbank functions: is the rise in systematic risk rewarded?. Managerial Finance, 29(8), 922. [AD11] 
VI CIDESPORT/2019

Congresso Internacional

de Desempenho Portuário

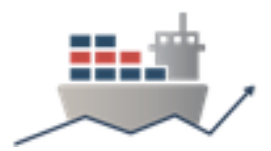

Pessanha, R. M., Gomes Filho, H., Júnior, L. P. Q., Neto, R. S., \& Oliveira, F. G. (2014). A Gênese do Complexo Logístico Industrial Porto do Açu: oportunidades e desafios para o desenvolvimento da Região Norte Fluminense. Revista Brasileira de Gestão e Desenvolvimento Regional, 10(2). [HP7]

Pipas, M. D. (2015). Interdependence between Management, Attitude and Organizational Behavior. Quality-Access to Success, 16. [AD12]

Randrianarisoa, L. M., \& Zhang, A. (2019). Adaptation to climate change effects and competition between ports: Invest now or later?. Transportation Research Part B: Methodological, 123, 279-322. [HP8]

Roberts, F.S. (1979). Measurement Theory, Addison-Wesley, Reading, MA.

Rodrigues, A. P., Fernandes, M. L., Rodrigues, M. F. F., Bortoluzzi, S. C., da Costa, S. G., \& Lima, E. P. (2018). Developing criteria for performance assessment in municipal solid waste management. Journal of Cleaner Production, 186, 748-757.

Roy, B. (1985). Méthodologie Multicritére d'Aide à la décision. Paris: Economica.

Sales, X., \& Carenys, J. (2012). Management control systems and strategy alignment after an MBO: A case study on the influence of the personal preferences of dominant individuals. Spanish Journal of Finance and Accounting/Revista Española de Financiación y Contabilidad, 41(155), 353-370. [AD13]

Staedele, A. E., Ensslin, S. R., \& Forcellini, F. A. (2019). Knowledge building about performance evaluation in lean production: an investigation on international scientific research. Journal of Manufacturing Technology Management, 30(5), 798-820.

Sun, C. C. (2011). Assessing Taiwan financial holding companies performance using window analysis and Malmquist productivity index. African Journal of Business Management, 5(26), 10508-10523. [AD14]

Tehrani, R., Mehragan, M. R., \& Golkani, M. R. (2012). Evaluating the performance of companies under the ownership of Razavi holding through data envelopment analysis. European Journal of Economics, Finance and Administrative Sciences, 49, 71-79. [AD15]

UNCTAD. Reveiw of Matitime Transport. 2019. Disponível em https://unctad.org/en/Pages/Publications/Review-of-Maritime-Transport\%28Series\%29.aspx. Acesso em 16 de ago. 2019.

Wang, W. K., Lu, W. M., \& Liu, P. Y. (2014). A fuzzy multi-objective two-stage DEA model for evaluating the performance of US bank holding companies. Expert Systems with Applications, 41(9), 4290-4297. [AD16]

Wang, S., \& Meng, Q. (2012). Liner ship route schedule design with sea contingency time and port time uncertainty. Transportation Research Part B: Methodological, 46(5), 615-633. [HP9]

Yeh, C. P., Wang, K. M., \& Chai, K. C. (2010). Measuring the efficiency of securities companies by corporate governance in a financial holding and non-financial holding system. Expert Systems with Applications, 37(6), 4671-4679. [AD17]

Zhu, D. S., Chen, Y. K., \& White, L. P. (2014). A study on profitability and marketability of Taiwanese bank firms before and after the Financial Holding Company Act. International Journal of Business Performance Management, 15(3), 207-228. [AD18]

Zurek, J. (1997). The privatization of Polish ports-the present situation and outlook for the future. Maritime Policy \& Management, 291-297. [HP10] 